\title{
A Review of Tip Clearance in Propeller, Pump and Turbine
}

\author{
Yabin Liu ${ }^{1}$, Lei Tan ${ }^{1, *(1)}$ and Binbin Wang ${ }^{2}$ (D) \\ 1 State Key Laboratory of Hydroscience and Engineering, Department of Energy and Power Engineering, \\ Tsinghua University, Beijing 100084, China; lyb15@mails.tsinghua.edu.cn \\ 2 Geochemical and Environmental Research Group, Texas A and M University, \\ College Station, TX 77845, USA; bwang314@tamu.edu \\ * Correspondence: tanlei@mail.tsinghua.edu.cn; Tel.: +86-10-6278-0605
}

Received: 17 July 2018; Accepted: 16 August 2018; Published: 22 August 2018

\begin{abstract}
Propellers, pumps, and turbines are widely applied in marine equipment, water systems, and hydropower stations. With the increasing demand for energy conservation and environmental protection, the high efficiency and the stable operation of pumps and turbine have been drawing great attention in recent decades. However, the tip clearance between the rotating impeller and the stationary shroud can induce leakage flow and interact with the main stream, introducing complex vortex structures. Consequently, the energy performance and the operation stability of pumps and turbines deteriorate considerably. Constant efforts are exerted to investigate the flow mechanism of tip-clearance flow and its induced influence on performance. However, due to various pump and turbine types and the complexity of tip-clearance flow, previous works are usually focused on a specific issue. Therefore, a systematic review that synthesizes the related research is necessary and meaningful. This review investigates related research in the recent two decades in the perspectives from fundamental physics to engineering applications. Results reveal the vortex types, trajectory, evolution, and cavitation behaviors induced by tip-clearance flow. It is concluded that the influence characteristics of tip clearance on energy performance are closely related to the machinery type. Tip-clearance size and tip shape are found to be crucial parameters for tip-leakage vortex (TLV). The proposed optimization schemes are also demonstrated to provide inspiration for future research. Overall, this review article provides a coherent insight into the characteristics of tip-clearance flow and the associated engineering-design applications. On the basis of these understandings, comments on conducted research and ideas on future research are proposed.
\end{abstract}

Keywords: tip clearance; cavitation; leakage flow; vortex; pump and turbine

\section{Introduction}

In recent decades, energy consumption has been rapidly increasing worldwide, while fossil energy sources have been gradually depleting and pollution exacerbated [1]. Consequently, the improvement of energy-conversion efficiency, the development of renewable clean energy, and population growth are drawing great attention [2]. Hydraulic machineries can be basically classified into two types, namely, pump and turbine, according to their energy-conversion direction. Pumps, in general, are machines that are widely used in industrial systems, such as water supply systems [3] and power station-cooling systems. Turbines are key components for energy conversion in hydropower stations. Several hydraulic machineries are used in special conditions, such as propulsor/waterjet pumps in marine equipment and pumps as turbines (PAT) in pumped-storage hydropower stations. With the increasing demand for energy conservation and environment-friendly engineering, it is desired to pursue high efficiency and stable operation of pumps and turbines. 
Unfortunately, tip clearance exists in the rotation component of pumps and turbines. Despite its small dimension, it seriously influences the energy performance and operation stability of pumps and turbines. In the recent two decades, significant advances in understanding the role of tip clearance in pumps and turbines have been achieved. Relevant studies include experimental and numerical approaches and focus on various aspects, from either the fluid-dynamics or engineering-design perspective. These diverse studies motivate this review paper, which aims to provide a coherent insight into several key research areas regarding the role of tip clearance.

Tip clearance (see Figure 1) is the gap between the blade tip and the casing wall in the rotating component of a pump or turbine, and it is unavoidable in most conditions [4]. As shown in Table 1, tip clearance can induce tip-leakage flow and further influence the energy performance and operation stability of pump and turbine. The head and efficiency can be significantly influenced by the variation of tip clearance $[5,6]$. Therefore, the appropriate design of tip clearance is necessary to optimize the performance of pumps and turbines.

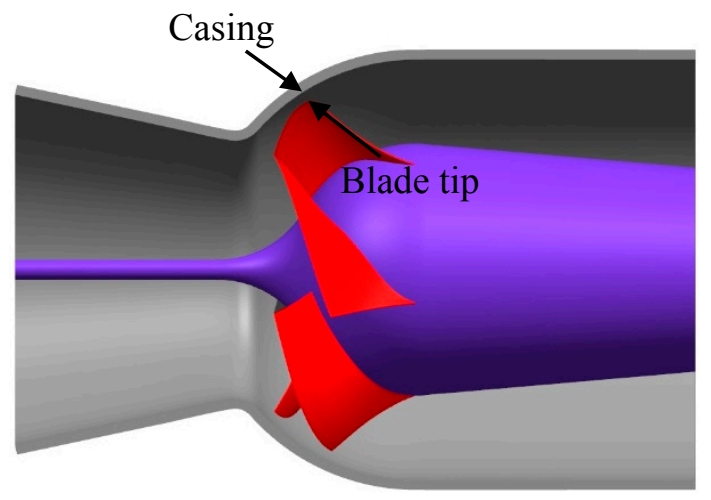

(a)

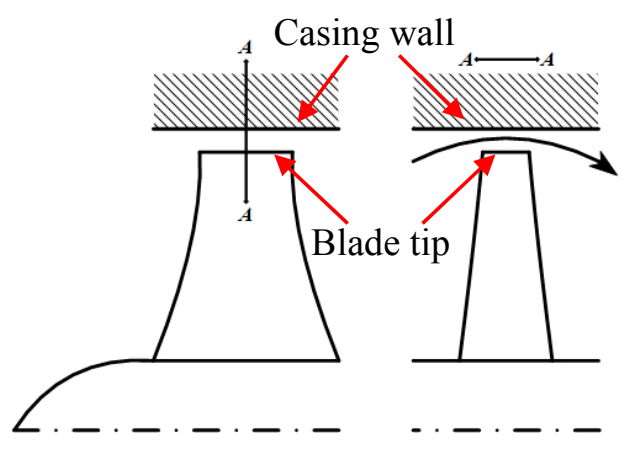

(b)

Figure 1. Tip clearance between blade tip and casing wall. (a) Three dimensional perspective; (b) two dimensional perspective.

Table 1. Examples of performance change in pump under the influence of tip clearance.

\begin{tabular}{cll}
\hline Tip-Clearance Range & Machinery Type & \multicolumn{1}{c}{ Performance Change } \\
\hline $0-1 \mathrm{~mm}$ & Mixed-flow pump [5,6] & $\begin{array}{l}\text { Head drops by 10\% at design flow rate; efficiency drops by 4\% } \\
\text { at design flow rate; pressure fluctuation near blade-trailing edge } \\
\text { increases by 20 times; unsymmetrical tip clearance deteriorates } \\
\text { cavitation performance and increases radial-force fluctuation. }\end{array}$ \\
\hline $0.5-1.5 \mathrm{~mm}$ & Mixed-flow pump [7] & $\begin{array}{l}\text { Head drops by about } 8 \% \text { at design flow rate; tip-leakage reverse } \\
\text { flow becomes stronger, and further thickens the casing } \\
\text { boundary layer and intensifies vortex in flow passage. }\end{array}$ \\
\hline $0-1 \mathrm{~mm}$ & Axial-flow pump [8] & $\begin{array}{l}\text { Significant pressure drop and cavitation inception in } \\
\text { tip-clearance region. }\end{array}$ \\
\hline $0-0.3 \mathrm{~mm}$ & Axial-flow pump [9] & $\begin{array}{l}\text { Head drops by 3\% at design flow rate; pressure fluctuation on } \\
\text { blade increases by 34\%. }\end{array}$ \\
\hline
\end{tabular}

Leakage flow through tip clearance interacts with the main flow and results in complex vortex structures and an unstable flow pattern in the tip-clearance region [7], such as cavitation [8] and pressure fluctuation [5,9]. Figure 2 illustrates the tip-leakage vortex (TLV) cavitation of an axial pump at cavitation number $(\sigma) 0.481$. TLV cavitation is mostly prone to occur at the tip-clearance region near the blade-suction side. This cavitation can lead to pressure fluctuations, vibrations, and fatigue failures for components. Figure 3 demonstrates the influence of tip clearance on the pressure fluctuations at the blade pressure surface for a mixed-flow pump. Intensified pressure fluctuation is presented in the impeller with the tip clearance, which can seriously deteriorate the operation stability of the pump. 


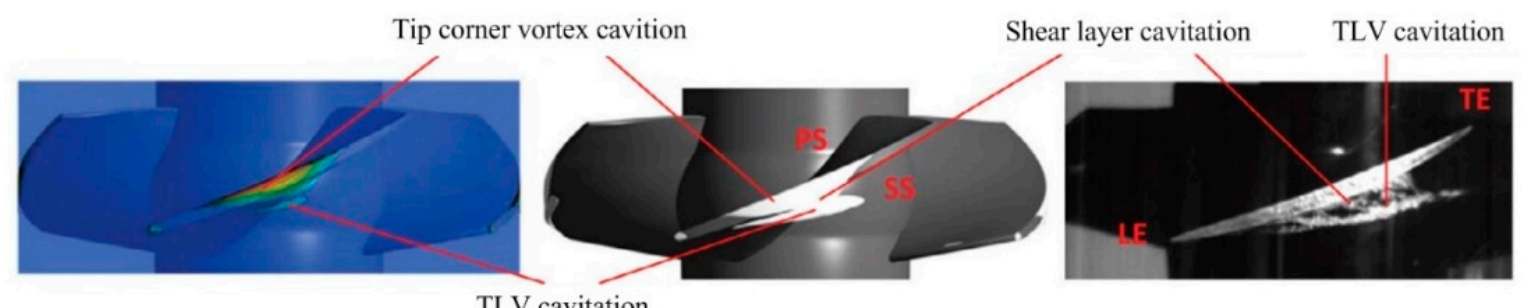

(a)

(b)

(c)

Figure 2. Tip leakage vortex (TLV) cavitation in an axial pump: (a) contours of vapor fraction in simulation; (b) isosurface of vapor fraction $\alpha_{\mathrm{v}}=0.1$ in simulation; (c) visualization of TLV cavitation in experiment [8]. PS: pressure side; SS: suction side; LE: leading edge; TE: trailing edge.

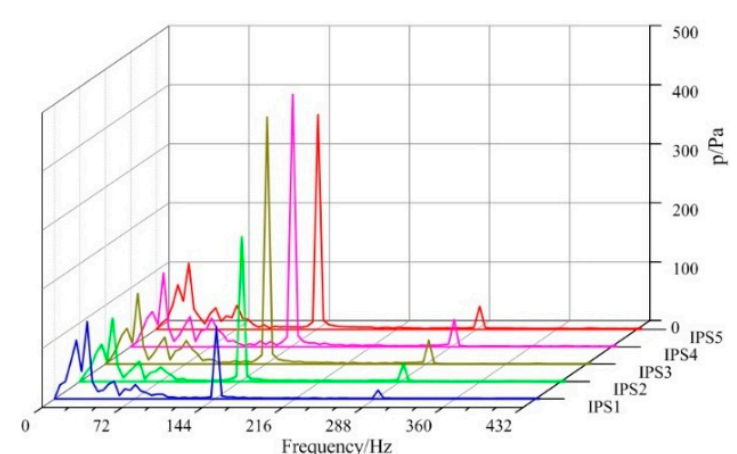

(a)

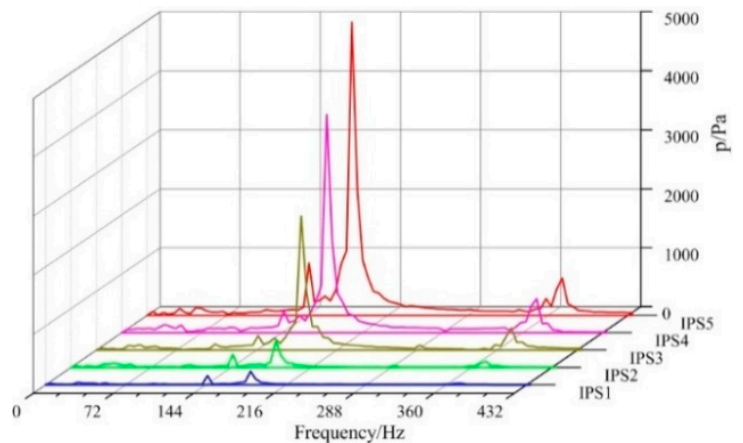

(b)

Figure 3. Comparison of pressure fluctuation on the blade pressure surface: (a) without tip clearance; (b) with tip clearance [5].

To date, numerous studies have been conducted to investigate the influence of tip clearance on the performance of pumps and turbines. Each investigation is usually specific to an application due to various pump and turbine types and the complexity of the tip-clearance flow. Therefore, a systematic review that synthesizes the related research is necessary and meaningful.

Figure 4 shows the structure of this review paper. It first focuses on the fundamental flow pattern under the influence of tip clearance. Section 2 presents the research and achievements on the flow mechanism of tip-clearance flow through experimental measurement. Section 3 provides a general review of the simulation work on the flow pattern induced by tip clearance under non-cavitation and cavitation conditions. Then, the influences of tip clearance on energy performance (Section 4) and operation stability (Section 5) are discussed. Finally, the key parameters and associated flow optimization with the tip clearance are presented in Section 6 to improve the flow pattern and performance of pumps and turbines. Therefore, the following four subjects are covered in this review paper:

(1) Flow mechanism and vortex dynamics in the tip-clearance region;

(2) Influence of tip clearance on the energy performance of pumps and turbines;

(3) Operation stability of pumps and turbines with tip clearance;

(4) Influence parameters of tip clearance and optimization strategies for propellers, pumps and turbines. 


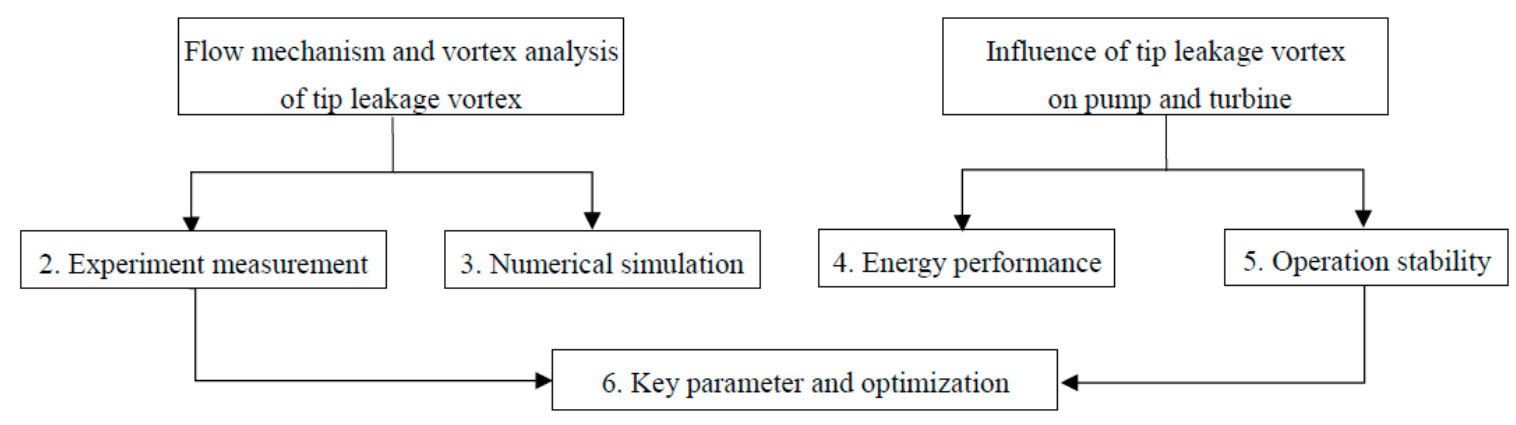

Figure 4. Sketch map of the paper structure.

This review follows a viewpoint from fundamental physics to engineering applications and summarizes the recent knowledge development on tip clearance in propellers, pumps, and turbines. Experimental and numerical studies have been intensively conducted. Thus, these two approaches are separately discussed in some of the relevant topics. Overall, the goal of this review paper is to provide a synthesized knowledge for the recent progress on tip clearance, which benefits the pump and turbine community.

\section{Experimental Study on Flow Mechanism near Tip-Clearance Region}

In applications, tip clearance causes significant energy losses in hydraulic machineries due to the deterioration of flow pattern. Therefore, the internal flow mechanism should be fully understood to propose corresponding optimization measures for energy saving. Given the complexity and importance of tip-clearance flow on the performance of hydraulic machineries, many researchers have conducted experimental studies on the flow patterns and evolution mechanism near the tip-clearance region in hydraulic machineries.

\subsection{Flow Pattern Near Hydrofoil}

Many studies have focused on hydrofoils due to their simple geometries and excellent visualization for flow patterns and evolution mechanism. Therefore, many researchers have conducted fundamental investigations on the flow around the hydrofoil with tip clearance, and this section provides related knowledge and discoveries. The TLV cavitation and tip vortex near the hydrofoil [10-13] have been well studied for various hydrofoil parameters, fluid properties, tip-clearance ranges, and flow conditions. Using laser Doppler velocimetry (LDV) in an elliptical hydrofoil, Boulon et al. [12] found that clearance size (confinement) influences the minimum pressure at the vortex core and the associated tip-vortex cavitation. A strong tip-vortex cavitation occurs in a tested range of clearance $(4-20 \mathrm{~mm}$ ) and diminishes when the clearance is outside the range (see Figure 5). In actual application, a hydrofoil may experience sustained oscillations and thus generate unsteady TLV cavitation. Murayama et al. [13] found that the TLV-cavitation pattern varies with the oscillation of the attack angle, and a phase difference exists between the TLV-cavitation variation and such an oscillation. The size of the TLV cavitation decreases with the increase in oscillating frequency.

Rather than a single-point measurement using LDV, particle-imaging velocimetry (PIV) provides two-dimensional or even three-dimensional velocity fields. In recent decades, PIV has been increasingly used in pumps and turbines. Dreyer et al. $[14,15]$ conducted stereo PIV measurements for the TLV, as illustrated in Figure 6. Taking advantage of high-speed flow visualization, the authors found remarkable impact of clearance size on the TLV trajectory; that is, the vortex becomes more distant from the hydrofoil with the decreasing tip-clearance size, and the changing tip clearance shifts the TLV trajectory after the trailing edge, as shown in Figure 7. 

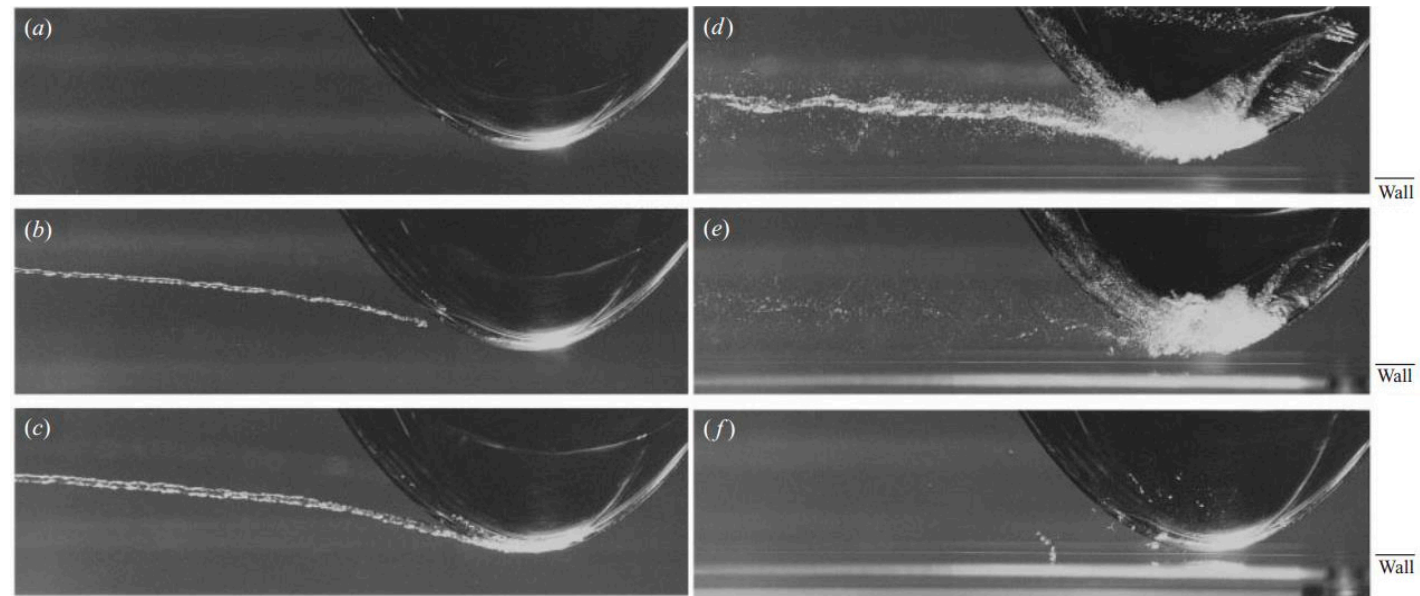

Figure 5. Visualizations of tip-vortex cavitation for different tip clearances: (a) $50 \mathrm{~mm}$; (b) $20 \mathrm{~mm}$; (c) $13 \mathrm{~mm}$; (d) $4 \mathrm{~mm}$; (e) $2 \mathrm{~mm}$; (f) $0.5 \mathrm{~mm}$ [12].

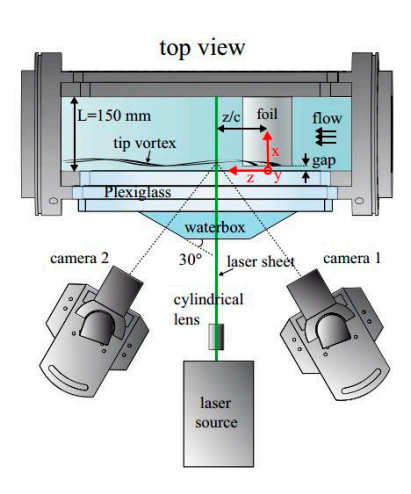

(a)

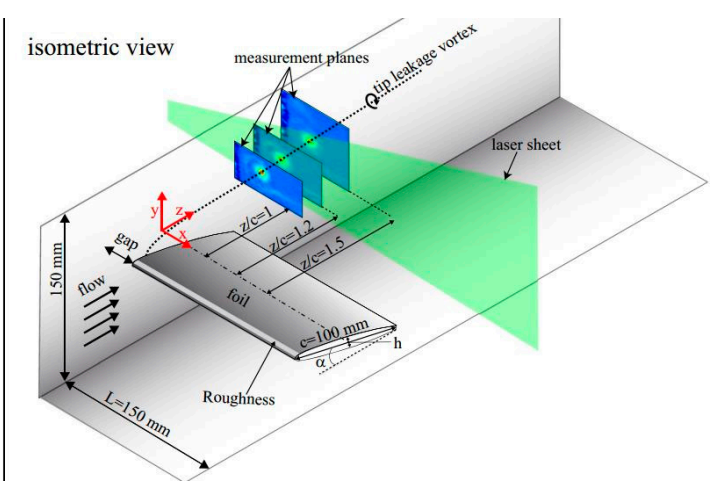

(b)

Figure 6. Sketch of the SPIV instrument. (a) top view; (b) isometric view [14].

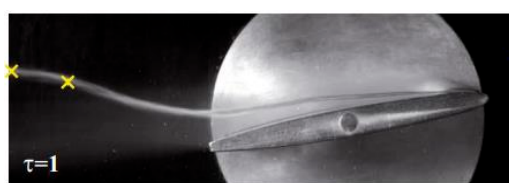

(a)

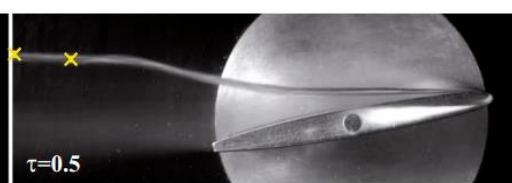

(b)

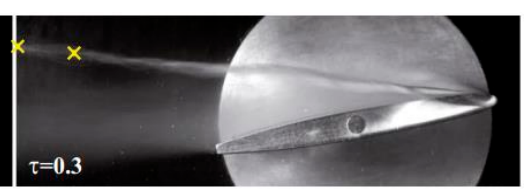

(c)

Figure 7. TLV Cavitation visualizations during $11 \mathrm{~ms}$ for three tip clearances. The two crosses are the locations $z / c=1$ and 1.2 [14]. (a) $\tau=1$; (b) $\tau=0.5$; (c) $\tau=0.3$.

\subsection{Two-Dimensional Structure and Evolution of Tip-Leakage Vortex (TLV)}

The tip-clearance flow is complex in rotation component of pumps and turbines. This paper provides an indepth survey of the TLV structure and evolution in different perspectives. From a twodimensional perspective, Miorini, $\mathrm{Wu}$, and Tan [16-22] systemically investigated the inner structure and turbulent evolution of TLV using PIV and high-speed imaging. For example, they conducted PIV measurements at several chord sections to observe the flow structure in an axial water-jet pump (see Figures 8 and 9). The authors found that the evolution of TLV could be divided into five periods. During the first period (period A), the formation of TLV begins at the blade tip near the suction side at approximately $30 \%$ chord and develops into a vortex at $50 \%$ chord while expanding in size remarkably. The development of vortices at $72 \%$ chord is divided into periods B, C, and D, corresponding to the shearing from the blade tip, the swirling around the vortex core, and vortex separation, respectively. 
When the vortices are separated from the shroud, positive vorticity appears during period D. On the blade-trailing edge section, the TLV is collapsed and dispersed between two blades, and vortices develop in the middle of the flow passage as they move closer to the adjacent blade (period E).
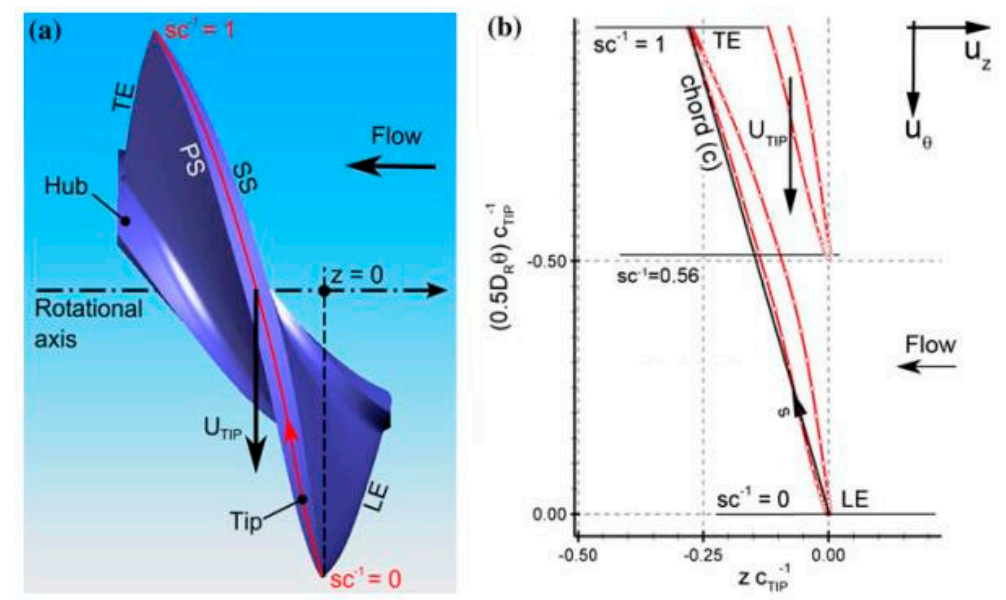

Figure 8. (a) Sketch of main components in impeller. (b) Tip profile curves [17]. $s$ is a coordinate aligned with the blade chord and $c$ is the chord length.
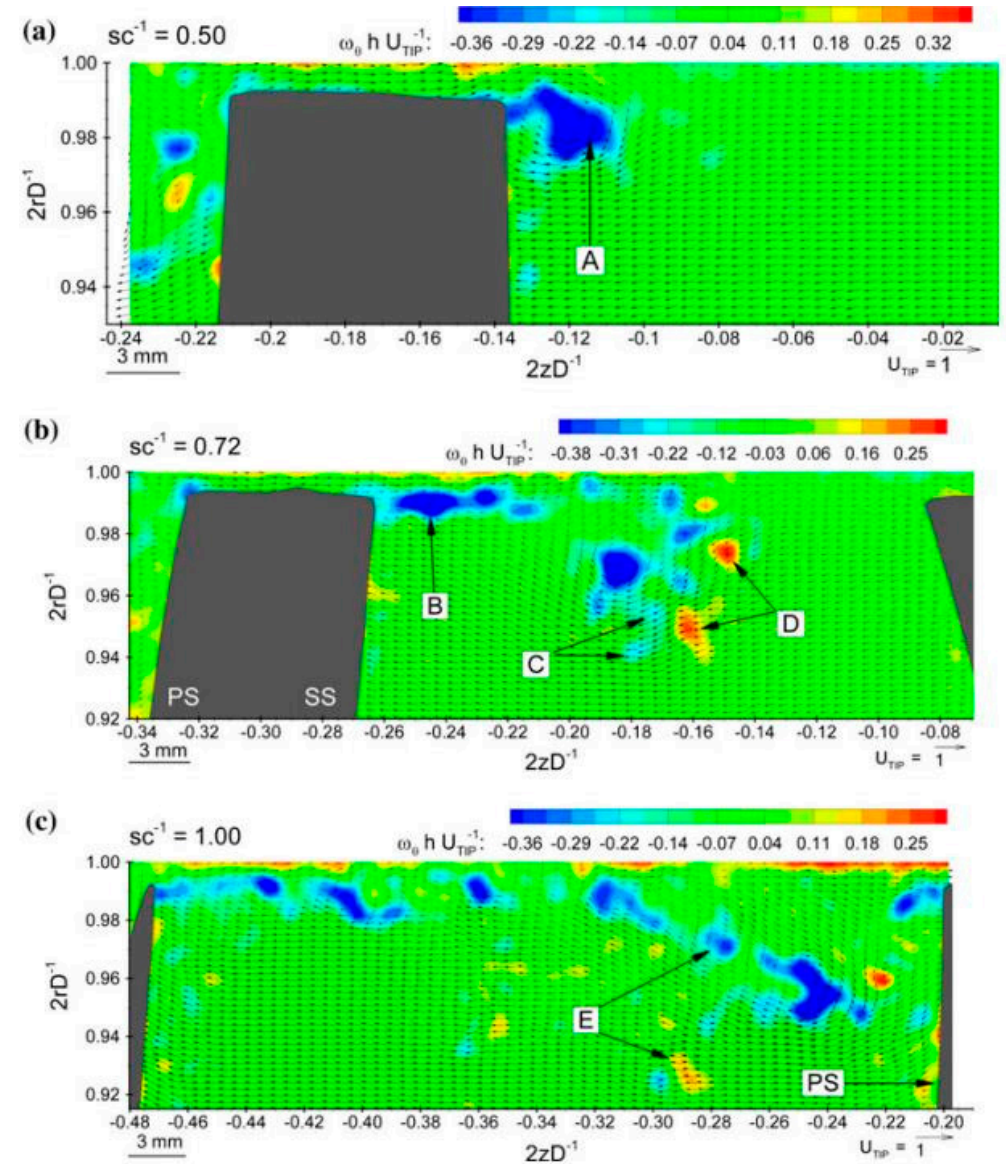

Figure 9. Transient state of TLV distributions at different chord sections [17]. (a) $\mathrm{sc}^{-1}=0.50$; (b) $\mathrm{sc}^{-1}=0.72 ;$ (c) $\mathrm{sc}^{-1}=1.00$. $D$ : casing diameter; $h$ : tip clearance size; $\omega_{\theta}$ : circumferential vorticity. 


\subsection{Three Dimensional Structure and Evolution of TLV}

The three-dimensional structure and the evolution of TLV have been recently documented using high-speed imaging [20-22]. Figure 10a presents the major vortex structure from 33\% chord to $67 \%$ chord, illustrating that the TLV gradually moves away from the blade along the blade chord. The observation also shows that the swirling direction of the peripheral vortex (marked in red) is completely different from that of the main TLV vortex, corresponding to period D (see Figure 10b). The TLV distribution near the middle chord is shown in Figure 10c. Secondary attached vortices form in the tip clearance, part of which are sucked into the main vortex. Figure 10d shows the vortex structure near the leading edge. The TLV collapses, and the resulting dispersed vortices are distributed in the near-blade region, corresponding to period $\mathrm{E}$.

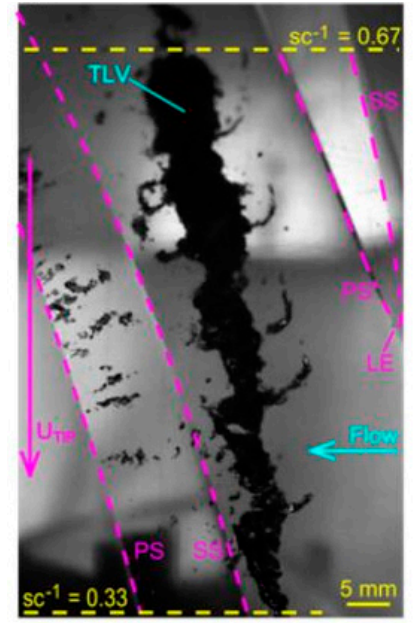

(a)

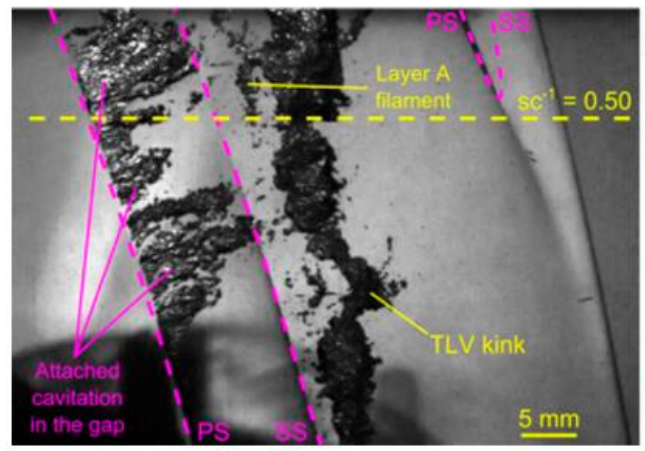

(c)

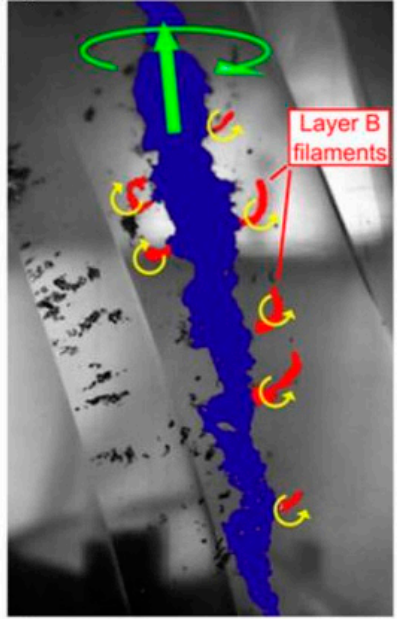

(b)

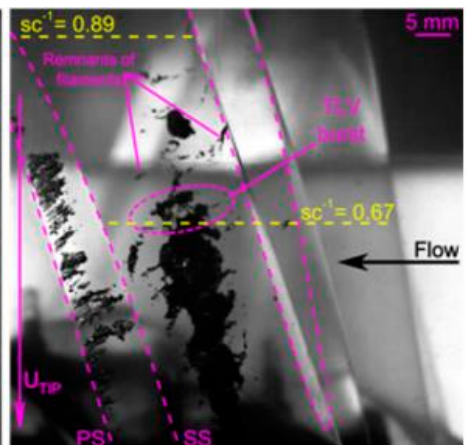

(d)

Figure 10. High-speed video images of the three-dimensional tip-leakage vortex [20]. (a) Tip leakage vortex; (b) Lay B filaments; (c) Lay A filaments; (d) Remnant filaments and burst. $s$ is a coordinate aligned with the blade chord; $c$ is the chord length; $U_{\text {tip }}$ tip velocity.

\subsection{Cavitation Behavior}

Pressure drop often occurs near the tip clearance due to the combined effect of leakage flow and the intensive rotation of the liquid around the vortex. This pressure drop can lead to serious cavitation in the operation of pump and turbine. Cavitation is known to cause intensive noise, vibration, and erosion for machinery components [23]. In an axial waterjet pump, Tan et al. [24] found that the apex angle between the perpendicular cavitation vortex (PCV) and the blade tip increases from $8^{\circ}$ to $12^{\circ}$ when the cavitation number varies from 0.39 to 0.45 , indicating a linear relationship in this range, as shown in Figure 11. Zhang et al. [8] investigated the patterns of TLV cloud cavitation in an axial 
flow pump. Their observation of the tip cavitation cloud in a period of $18 \mathrm{~ms}$ (see Figure 12) shows that TLV cloud cavitation maintains a persistent triangular structure from the leading edge to $80 \%$ chord. A definite trajectory is not observed starting from the $80 \%$ chord (see the circle in Figure 12), and the cavitation pattern dramatically changes from then. These results demonstrate a definite triangular structure for the most part of TLV cloud cavitation, but the cavitation pattern is unstable near the trailing edge.

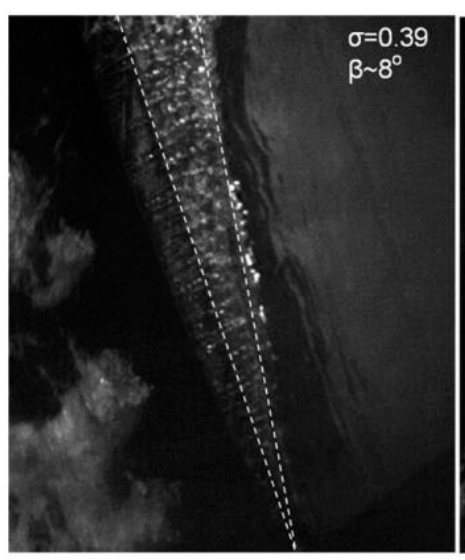

(a)

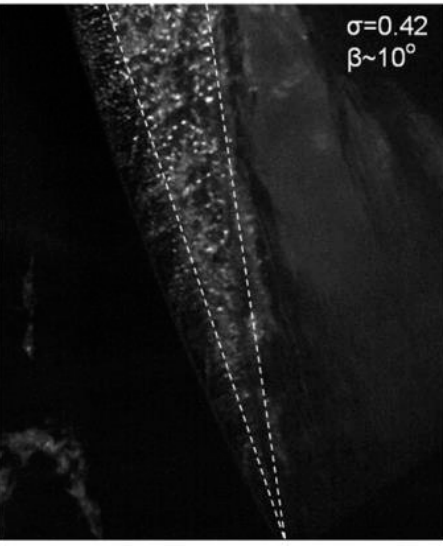

(b)

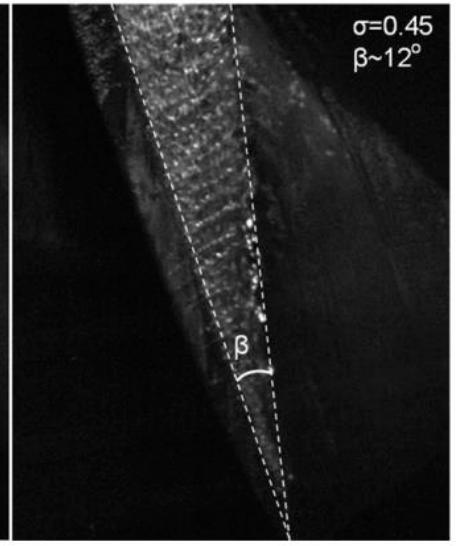

(c)

Figure 11. High-speed video images of cavitation pattern with different cavitation number [24]. (a) $\sigma=0.39$; (b) $\sigma=0.42$; (c) $\sigma=0.45$. $\sigma$ : cavitation number; $\beta$ : apex angle.

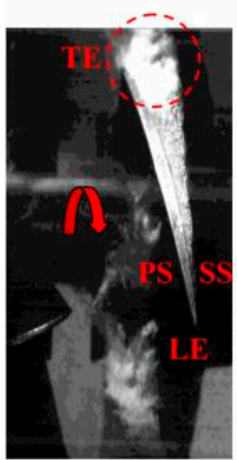

$T=0 \mathrm{~ms}$

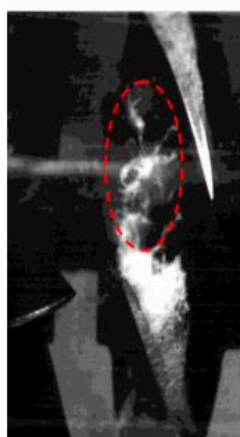

$T=5 / 9 T$

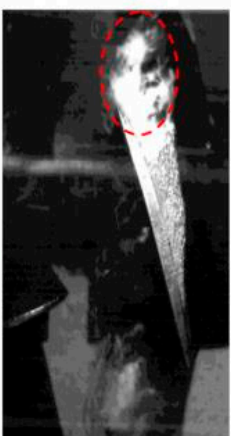

$t=1 / 9 T$

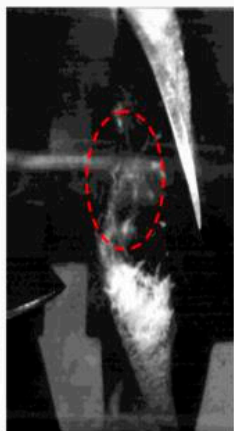

$t=6 / 9 T$

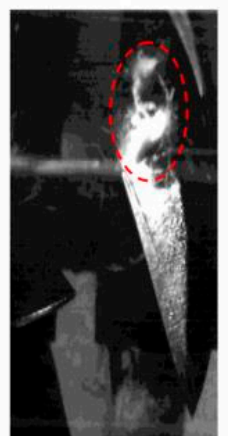

$t=2 / 9 T$

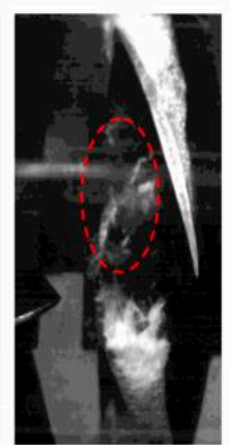

$t=7 / 9 T$
Vortices cavitation

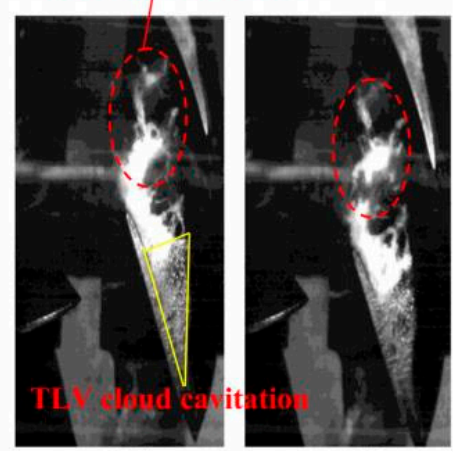

$t=3 / 9 T$

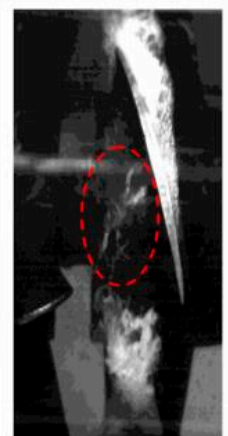

$t=8 / 9 T$ $t=4 / 9 T$

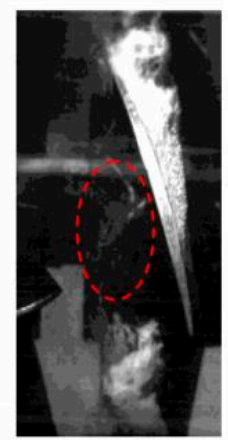

$t=T$

Figure 12. TLV cloud cavitation in an axial flow pump at $\sigma=0.262$ [8].

As summarized in Table 2, the above experimental studies reveal the flow structure in the tip-clearance region from single hydrofoils to rotating pump and turbines. Studies on the flow structure 
in hydrofoils have demonstrated the basic characteristics of TLV and the associated cavitation behaviors. Qualitative and quantitative investigations provide an important basis for the engineering design, TLV trajectory at different blade-chord frictions, cavitation patterns for different tip-clearance sizes, and variation of cavitation size with blade movement, among others. In addition, these measurements provide valuable validation data for numerical simulation, which is another important tool in pump and turbine research.

Table 2. Main experiment studies on tip-clearance flow.

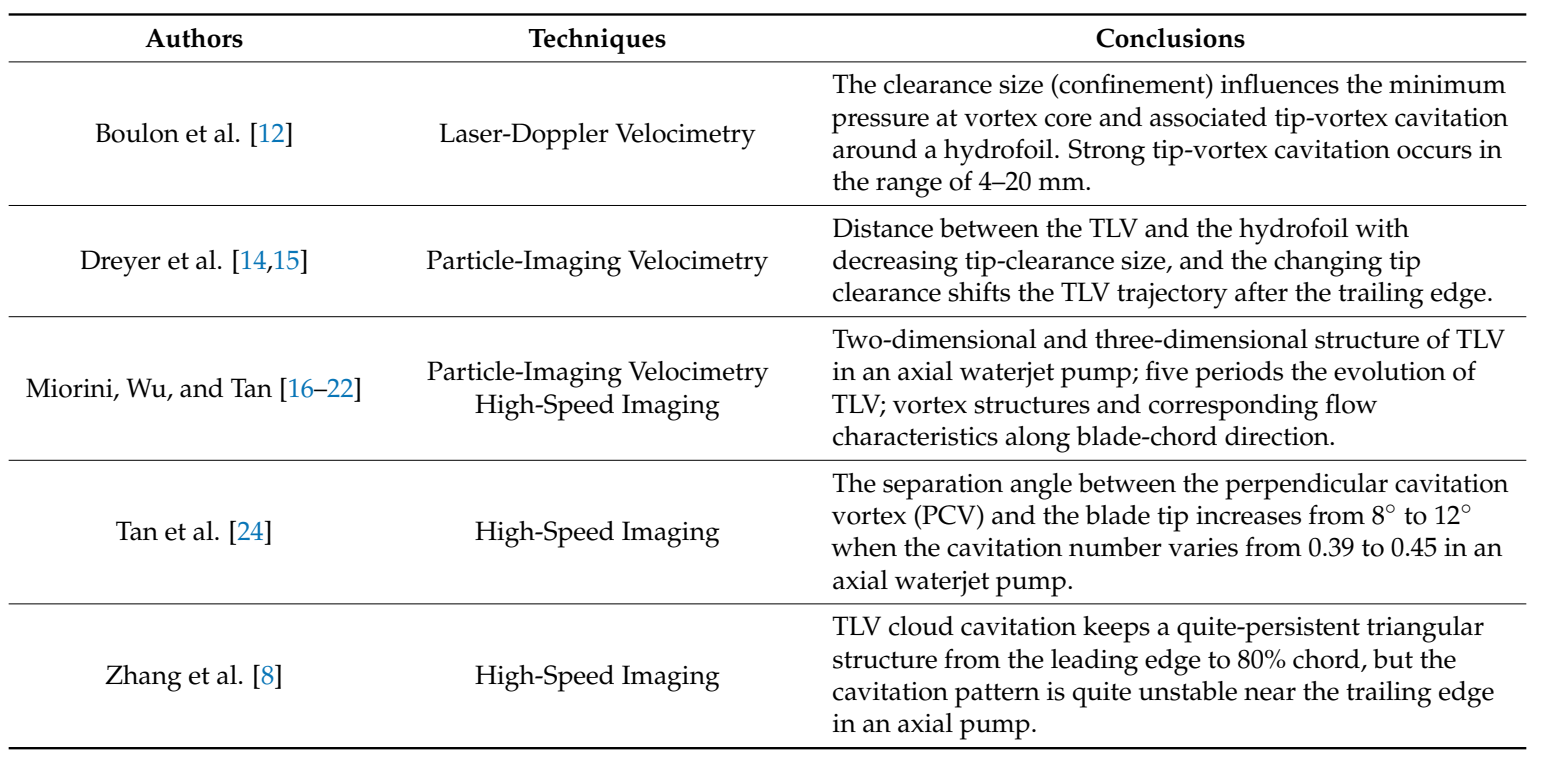

\section{Numerical Study on Flow Mechanism near Tip-Clearance Region}

Numerical simulation can provide full parameters in flow field. Thus, computational fluiddynamics modeling is an important element in current engineering design. Particularly in pumps and turbines, when accessing the flow field near the tip-clearance region is experimentally difficult, validated numerical simulation is a more practical approach. This section first focuses on the numerical method validation and then provides indepth knowledge on the vortex characteristics induced by tip clearance, such as vortex classification, trajectory, and associated cavitation.

\subsection{Comparison and Validation of Numerical Methods}

Among the numerous turbulence models, Reynolds-averaged Navier-Stokes (RANS) and large eddy simulation (LES) are widely applied in simulating the TLV and cavitation evolution [25-27]. To capture the tip-vortex details, grid refinement in the region near the blade tip is a useful treatment, which can be determined from the calculated velocity and vorticity [28].

To obtain reliable flow details near the tip clearance, the accuracy of the simulation method should be validated. On the basis of the shear stress transport (SST) $k-\omega$ model, Decaix et al. [29] validated the tip-vortex trajectory using RANS (see Figure 13). Szantyr et al. [30] compared four turbulence models (i.e., standard $k-\varepsilon$, renormalization group (RNG) $k-\varepsilon$, SST $k-\omega$, and Reynolds stress model) with the measurement. They concluded that RNG $k-\varepsilon$ is the best for simulating the tip-vortex cavitation, and SST $k-\omega$ is optimal under the noncavitation condition [27]. RANS and LES were compared to quantify the flow parameters [31,32]. In general, each model has its own advantages, but no universal model has been suggested. Readers may refer to References [29-32] for more details. To study the TLV cavitation around the same hydrofoil, a rotation-curvature-corrected SST model is applied in the numerical calculation, and results show that this model increases the prediction accuracy for cavitation patterns at large tip clearances [33]. 


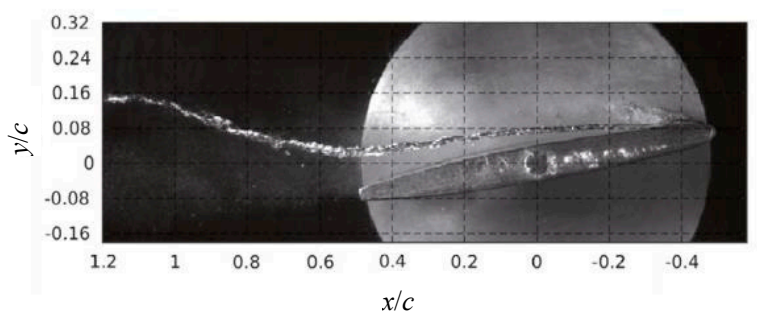

(a)

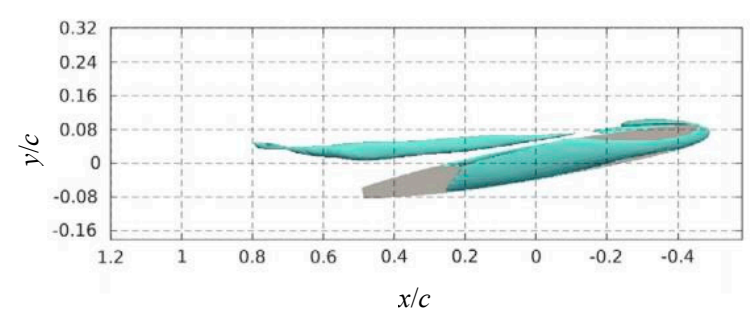

(b)

Figure 13. Comparison between numerical results and experiment results: (a) high-speed video images of tip-vortex trajectory; (b) cavitation cloud calculated using Reynolds-averaged Navier-Stokes (RANS) [29].

\subsection{Vortex Types and Corresponding Characteristics}

Vortex structures induced by tip clearance are complicated due to the interaction with the main stream and other vortex types. Therefore, the basic vortex types and their corresponding characteristics should be clarified. You and Moin [34-41] systematically analyzed the flow pattern near the tip clearance in a turbomachinery and its temporal and spatial evolution. They developed an LES code using immersed boundary and grid refinement, and validated the code using the measurement data [34]. Thereafter, they applied the LES method to study the tip-clearance flow mechanism in hydraulic turbomachines [35,36]. As shown in Figure 14, the tip-clearance flow can be divided into three parts: the TLV, the tip-separation vortex, and the induced vortex. The TLV occupies the largest flow volume. It originates at approximately $30 \%$ chord from the leading edge and expands along the flow direction. The separation vortex is mainly located in the flow passage after the leading edge and interferes with the TLV. The induced vortex has a reversed swirling direction relative to the TLV. The induced vortex has been identified as the peripheral vortex in experiments (see Figure 10b) that usually occupies the smallest flow volume and dissipates close to the adjacent blade.

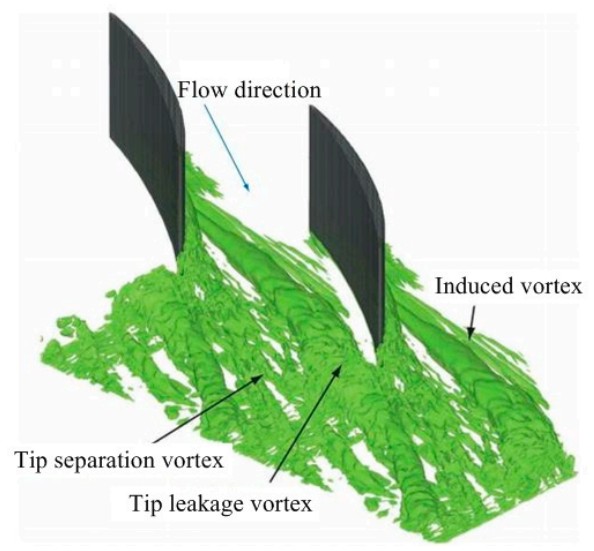

Figure 14. Three-dimensional structure of tip-clearance flow based on large eddy simulation (LES) [36].

These complicated vortexes have a remarkable influence on the flow pattern. Studies on the mechanisms of viscous losses [39-41] show that the TLV and leakage flow can lead to violent turbulence intensity, which increases the viscous losses near the tip clearance. Using the results from numerical simulation, You et al. proposed strategies to improve the engineering design, such as optimizing the direction of leakage flow by changing the tip shape.

The TLV starts at approximately $30 \%$ chord, and this process can significantly decrease the pressure in this region. Therefore, the cavitation is mostly prone to occur at the center of the TLV on the $30 \%$ chord section (see Figure 15a). At the same region, the most intensive pressure fluctuations 
(see Figure 15b) likely lead to strong vibration and considerable noise. Thus, special attention should be given to the fluid state at approximately $30 \%$ blade chord in future research.

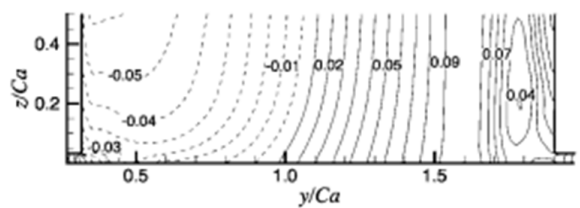

(a)
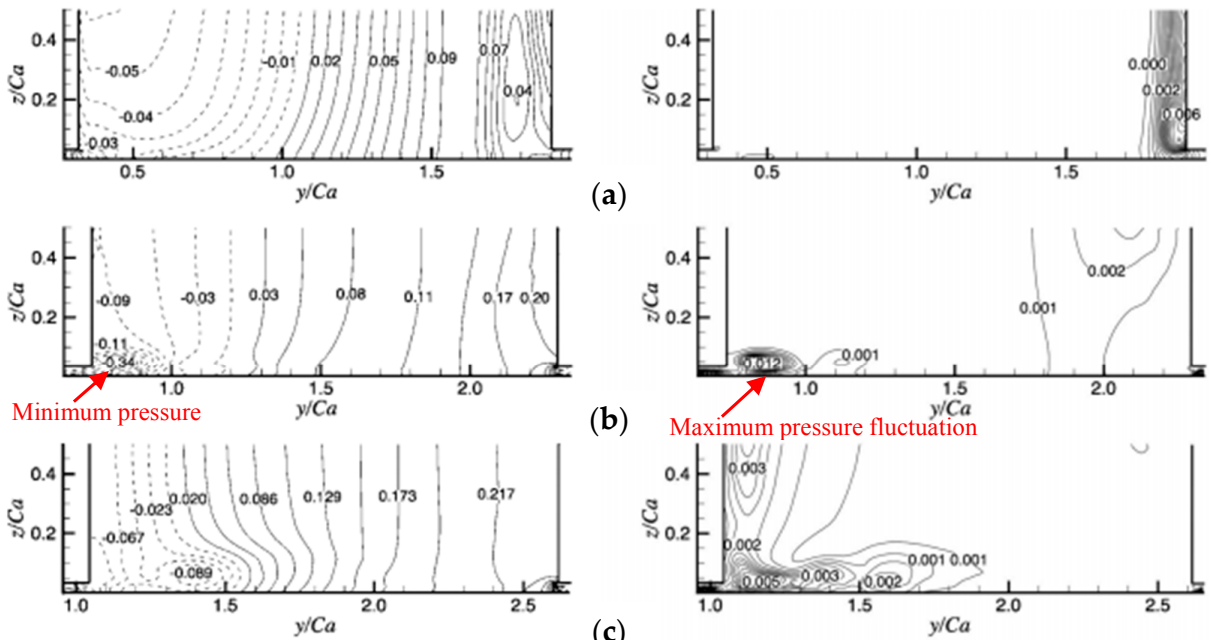

(b)
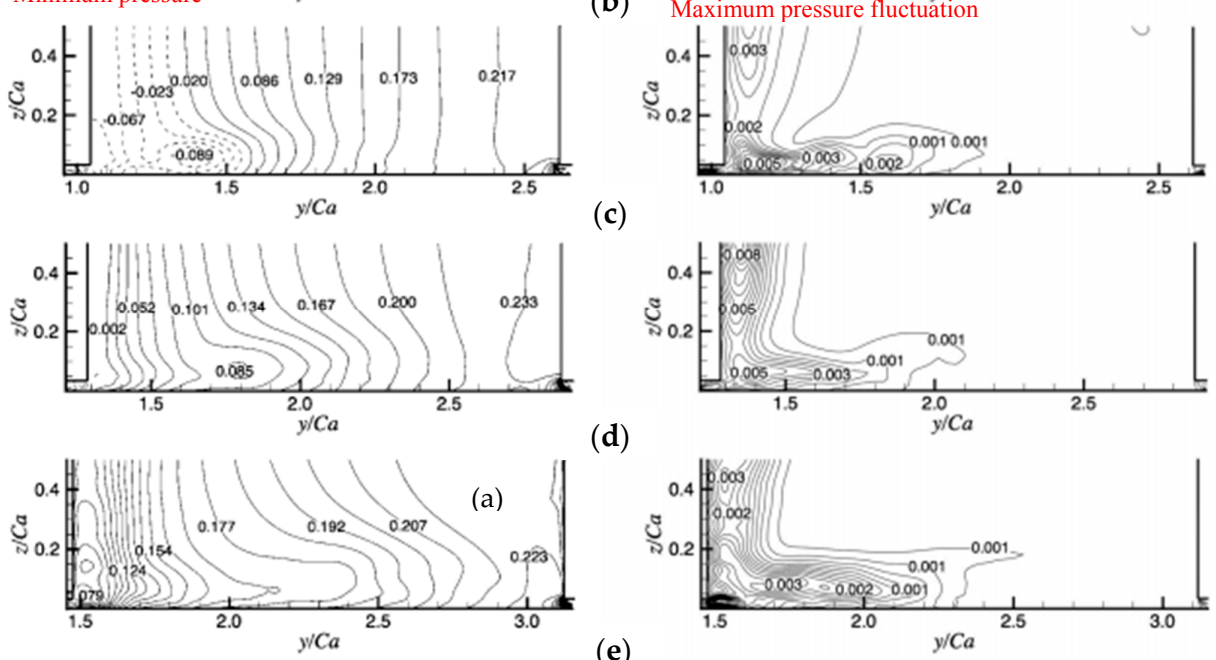

(d)

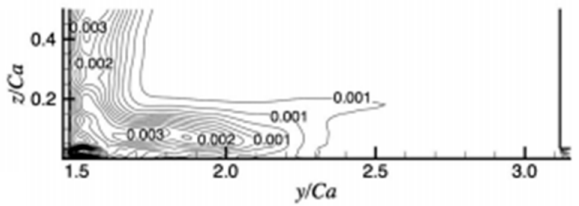

(e)

Figure 15. Distribution of mean pressure and pressure fluctuations: (a) 10\% chord; (b) 30\% chord; (c) $50 \%$ chord; (d) $70 \%$ chord; and (e) $90 \%$ chord [41].

\subsection{TLV Trajectory and Related Factors}

As mentioned in Section 3.1, the TLV is the dominant structure among these vortexes induced by tip clearance. The trajectory of TLV will significantly influence the workability and flow instability in the flow passage. By using both numerical and experimental methods, Zhang et al. [42] investigated the characteristics of TLV trajectory and associated cavitation structures in an axial pump. As shown in Figure 16, the streamlines twist through each section, and the center of the streamlines corresponds to the maximum swirling strength. The model and observation of the TLV trajectory show remarkable agreement. The comparison of TLV trajectories indicates that flow rate has significant impacts on the formation and evolution of TLV. When the flow rate increases from $0.85 Q_{\mathrm{d}}$ to $1.2 Q_{\mathrm{d}}$, the formation point of TLV shifts from the leading edge of $5 \%$ chord to $40 \%$ chord. Meanwhile, the separation angle between the TLV and the blade tip shows an increasing trend with the increasing flow rate, as shown in Figure 17. However, Liu et al. [5] found that the separation angle between the TLV and the blade tip remains at $10^{\circ}$ for different tip-clearance sizes at the design flow rate in a mixed-flow pump, as shown in Figure 18. This discrepancy suggests that the separation angle is likely dependent on the flow rate and not on tip-clearance size. As shown in Figure 19, TLVs are classified into four categories, namely, primary, secondary, entangled, and dispersed TLVs, and the corresponding vortex-derivation mechanism is analyzed by the relative vorticity transport equation. A remarkable relationship between the flow rate and the TLV trajectory can be observed, and the inception point of the primary TLV changes to approximately $20 \%$ chord under a large flow rate [43]. 


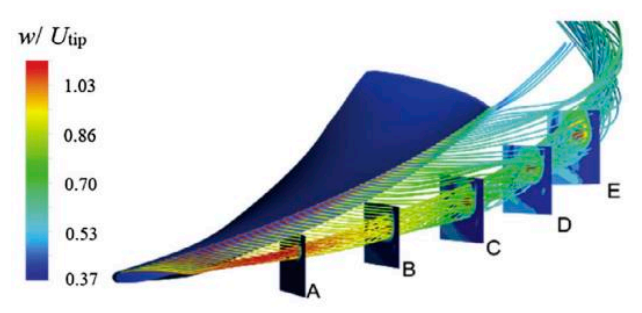

(a)

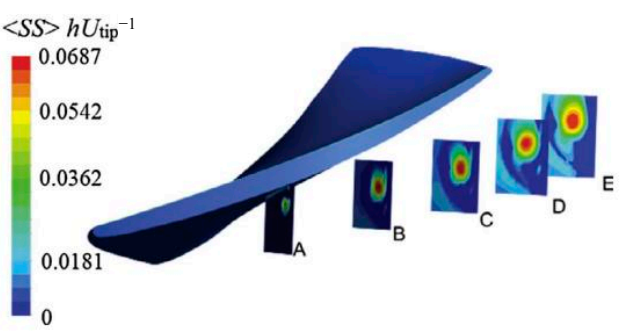

(b)

Figure 16. Streamlines and contours of swirling strength on different chord sections [42]. (a) Streamlines and swirling strength contours; (b) swirling strength contours.

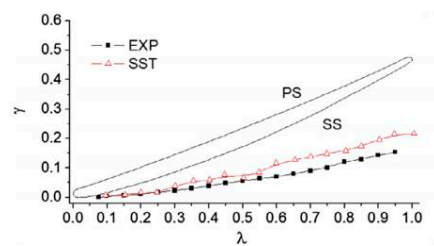

(a)

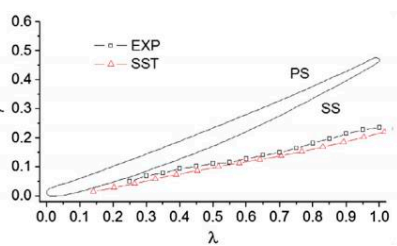

(b)

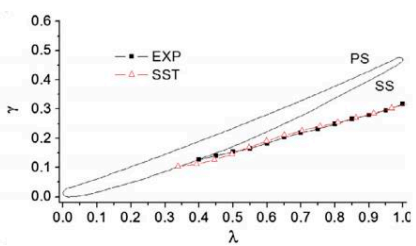

(c)

Figure 17. Comparison of TLV trajectories based on numerical and experimental results at different flow rates. $\lambda$ is blade chord fraction, $r$ is radius [42]. (a) $0.85 Q_{\mathrm{d}} ;$ (b) $1.0 Q_{\mathrm{d}} ;$ (c) $1.2 Q_{\mathrm{d}}$. EXP: experiment results; SST: simulation results using shear stress transport.

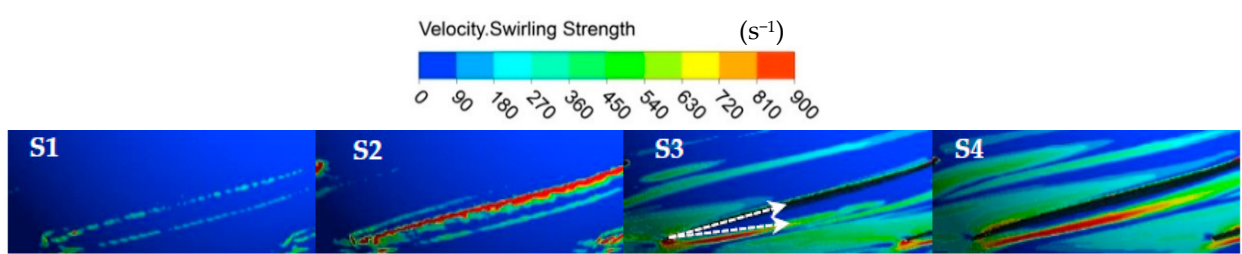

(a)

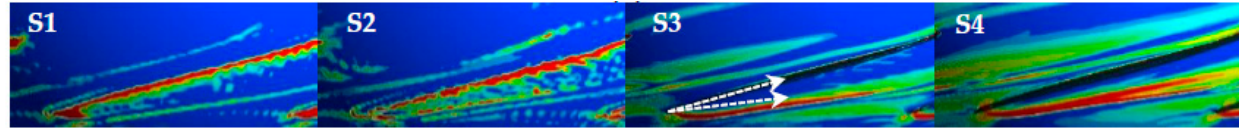

(b)

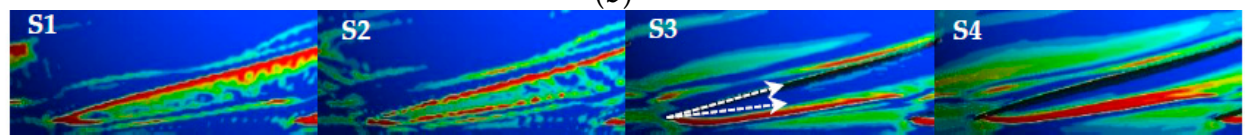

(c)

Figure 18. Distribution of swirling strength and separation angels on different circumferential sections for different tip clearances: (a) $0.2 \mathrm{~mm}$; (b) $0.65 \mathrm{~mm}$; (c) $1.0 \mathrm{~mm}$ [5].

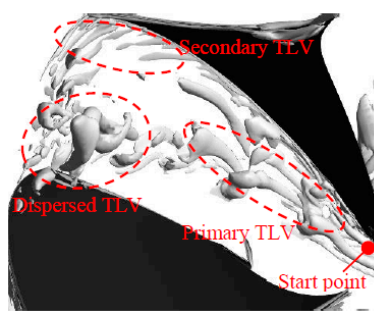

(a)

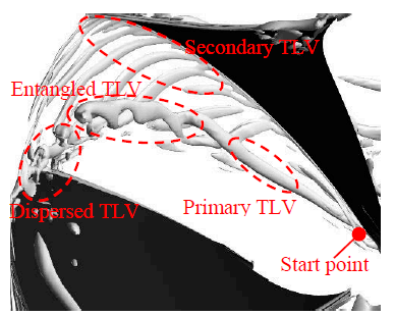

(b)

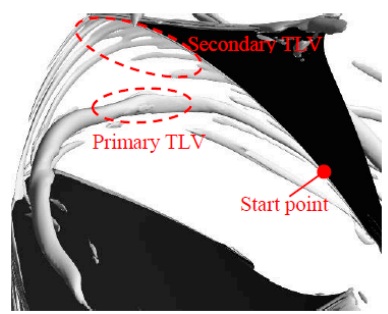

(c)

Figure 19. Vortex structure defined by $Q$ criterion for three flow rates [43]. (a) $0.8 Q ;$ (b) $1.0 Q ;$ (c) $1.2 Q$. 


\subsection{Cavitation Behavior}

When cavitation occurs, the TLV structure becomes more complex. As shown in Figure 20, the TLV develops from the blade-leading edge to the middle of the flow passage (S1 to S3), expanding in size. While approaching the adjacent blade, the TLV decays and collapses due to the tip-clearance flow and the interaction with the main flow. The sheet cavitation originating from the primary blade interacts with the TLV cavitation cloud between S3 and S4. A new cavitation cloud called PCV develops toward the adjacent blade, continuously changing its size and direction along the development. When the PCV is near the adjacent blade, it is thickened, and the direction is nearly perpendicular to the suction side of the adjacent blade.

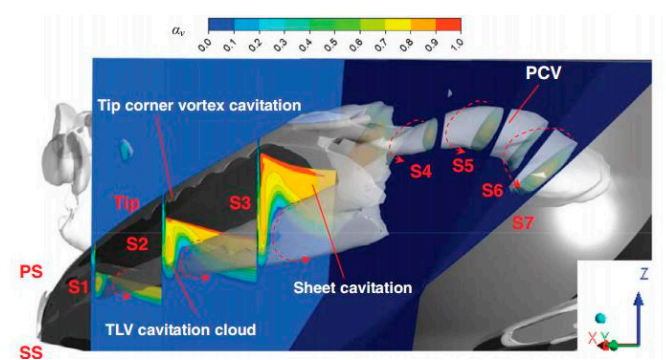

(a)

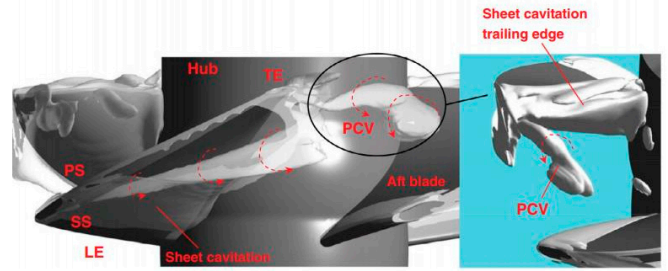

(b)

Figure 20. Isosurface of $\alpha_{\mathrm{v}}=0.1$, contoured by vapor volume fraction in an axial pump at cavitation number $\sigma=0.262$ [44]. (a) Vapor volume fraction contours; (b) TLV cavitation cloud. S1-S7: symbols of cross sections; $\alpha_{\mathrm{v}}$ : vapor volume fraction. PCV: perpendicular cavitation vortex.

To investigate the cavitation evolution under the impact of tip clearance in a three-dimensional inducer, Okita et al. [45] used the detached eddy-simulation model to calculate the flow field near the tip clearance. This model combines RANS in the near wall and LES in the turbulence region. As shown in Figure 21, the tip-vortex cavitation extends to the center of the flow passage. A horseshoe-shaped structure is present near the casing wall at the leading edge under the impact of tip-clearance flow. Therefore, more streamlines are blocked at the leading edge, flow is more turbulent, and the interaction is more intensive after bypassing the cavitation cloud.

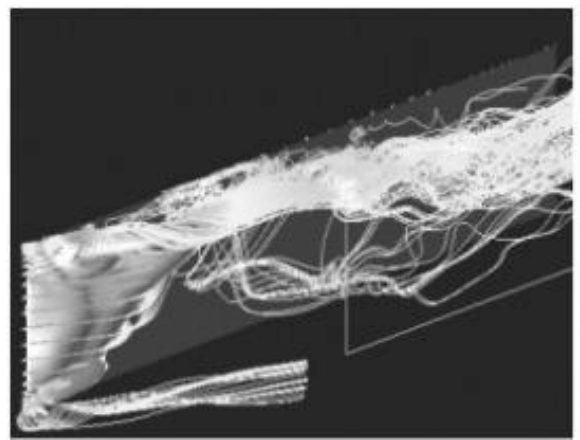

(a)

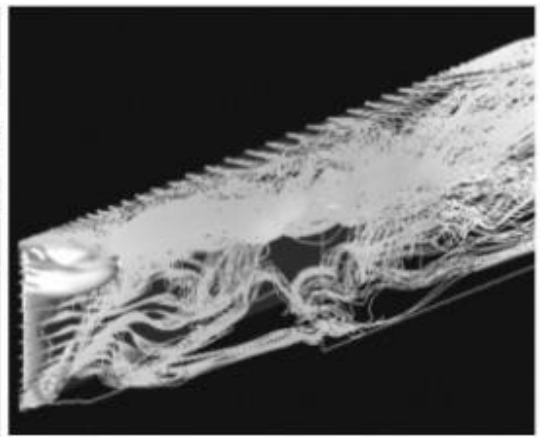

(b)

Figure 21. Comparison of cavitation structure and streamlines: (a) without tip clearance; (b) with tip clearance [45].

The abovementioned work is summarized in Table 3, which illustrates the capability of the numerical simulation in resolving the temporal and spatial dynamics of the TLV structure. These results show that the vortex structures in pump and turbine can be categorized into tip leakage, tip separation, and induced vortexes. The TLV and leakage flow lead to violent turbulence intensity and remarkably increase the viscous losses near the tip clearance. The TLV trajectory is closely related to the flow 
rate, which affects the start point and separation angle of TLV. Cavitation is mostly prone to occur at the TLV core and on the blade-chord section where the TLV starts. The cavitation originating from the TLV cavitation and the sheet cavitation evolve from a location that is parallel with the primary blade to perpendicular to the adjacent blade, forming the perpendicular-cavitation vortex. On the basis of numerical results, an indepth and detailed knowledge on tip-clearance flow and its evolution mechanism is obtained, which greatly contributes to the suppression of tip-clearance flow and improvement of machine performance.

Table 3. Main numerical studies on tip-clearance flow.

\begin{tabular}{|c|c|c|}
\hline Authors & Method and Object & Conclusions \\
\hline You and Moin [34-38] & $\begin{array}{l}\text { LES model } \\
\text { Hydraulic turbomachine }\end{array}$ & $\begin{array}{l}\text { The tip-clearance flow can be divided into three parts: the } \\
\text { tip-leakage vortex, the tip-separation vortex, and the induced } \\
\text { vortex. The three parts vary in volume and swirling direction, and } \\
\text { TLV is the dominant structure among them. }\end{array}$ \\
\hline You and Moin [39-41] & $\begin{array}{l}\text { LES model } \\
\text { hydraulic turbomachine }\end{array}$ & $\begin{array}{l}\text { Tip-clearance flow leads to violent turbulence intensity, which } \\
\text { increases the viscous losses near the tip clearance; Optimizing the } \\
\text { direction of leakage flow by changing the tip shape is proposed; } \\
\text { Cavitation is mostly prone to occur at TLV core in inception stage, } \\
\text { and local optimization is recommended. }\end{array}$ \\
\hline Zhang et al. [42] & $\begin{array}{l}\text { SST model } \\
\text { Axial pump }\end{array}$ & $\begin{array}{l}\text { When the flow rate increases from } 0.85 Q_{\mathrm{d}} \text { to } 1.2 Q_{\mathrm{d}} \text {, the formation } \\
\text { point of TLV shifts from } 5 \% \text { blade chord to } 40 \% \text { blade chord. } \\
\text { The separation angle between the TLV and blade tip shows an } \\
\text { increasing trend with increasing flow rate. }\end{array}$ \\
\hline Liu et al. [5] & $\begin{array}{l}\text { RNG model } \\
\text { Mixed-flow pump }\end{array}$ & $\begin{array}{l}\text { The separation angle between the TLV and the blade tip remained } \\
10^{\circ} \text { for different tip-clearance sizes at the design flow rate. } \\
\text { The separation angle is likely dependent on the flow rate [39], } \\
\text { not the tip-clearance size [2]. }\end{array}$ \\
\hline Liu et al. [43] & $\begin{array}{l}\text { LES model } \\
\text { Mixed-flow pump }\end{array}$ & $\begin{array}{l}\text { the TLV is classified into four categories, namely, primary TLV, } \\
\text { secondary TLV, entangled TLV, and dispersed TLV; } \\
\text { the corresponding vortex derivation mechanism is analyzed by } \\
\text { the relative vorticity transport equation. }\end{array}$ \\
\hline Zhang et al. [44] & $\begin{array}{l}\text { SST model } \\
\text { Axial pump }\end{array}$ & $\begin{array}{l}\text { The evolution of cavitation patterns related to tip-clearance flow, } \\
\text { including TLV cavitation cloud, perpendicular cavitation vortex, } \\
\text { and sheet cavitation. There are interactions among these } \\
\text { cavitation patterns. }\end{array}$ \\
\hline Okita et al. [45] & $\begin{array}{l}\text { DES model } \\
\text { Three-dimensional inducer }\end{array}$ & $\begin{array}{l}\text { A horseshoe-shaped cavitation structure is observed near the } \\
\text { casing wall at the leading edge under the impact of tip-clearance } \\
\text { flow. This structure makes more streamlines blocked at the } \\
\text { leading edge and flow interaction more intensive. }\end{array}$ \\
\hline
\end{tabular}

\section{Energy Performance of Pumps and Turbines with Tip Clearance}

In Section 3, the strong impact of tip clearance on flow pattern in many pump and turbine types is demonstrated. The deterioration in flow state is bound to decrease energy performance. Hence, quantitative relationships between the tip clearance and energy performance must be established. The influence of tip clearance may vary due to the various pump and turbine types with different operation characteristics. Consequently, the flowing depictions are presented according to different machinery types, including conventional pump, conventional turbine, inducer, and other types.

\subsection{Energy Characteristics in Pumps}

First, the influence of tip clearance on energy performance of pumps is investigated. Saha and coworkers [46,47] conducted experiments to investigate the hydraulic performance and flow characteristics in a mixed-flow pump with different tip clearance sizes. In Figure 22, $H$ denotes the pump head, $N$ denotes the rotating speed of the impeller, $U_{\mathrm{T}}$ denotes the blade speed of the rotor outlet tip, $D$ denotes the diameter of the impeller tip at the outlet, $\eta_{\mathrm{H}}$ denotes the hydraulic efficiency, $t_{\mathrm{c}}$ denotes the tip-clearance size, and $C_{\text {tip }}$ denotes the tip chord. Therefore, the three expressions, $H /\left[U_{T}^{2} /(2 g)\right], Q /\left(N D^{3}\right)$, and $t_{c} / C_{\text {tip }}$, in Figure 22 denote the normalized pump head, flow rate, 
and tip-clearance size, relatively. It is indicated that the pump efficiency and the pump head are nearly linearly related to the tip-clearance size near the design flow rate. This observation is consistent with the numerical simulation result [5]. However, the descent slopes of the head are different between References [47] and [5], which may be ascribed to the operating conditions and the tip-clearance ranges.

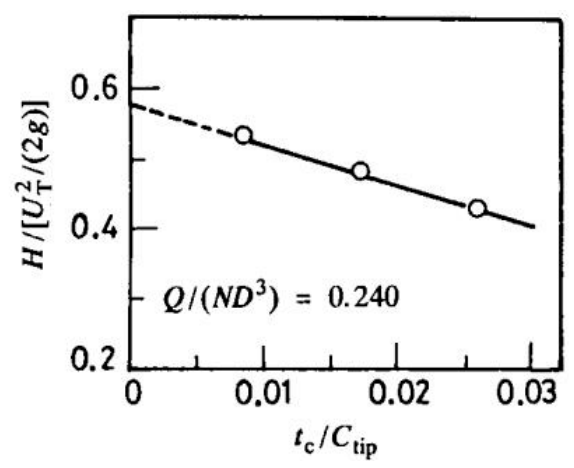

(a)

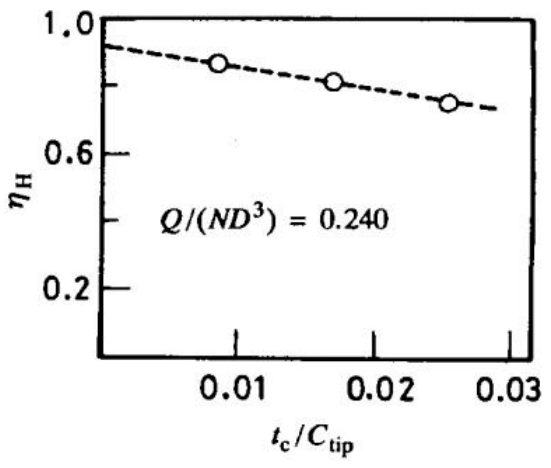

(b)

Figure 22. Pump head and efficiency versus tip-clearance size near design flow rate: (a) head; (b) efficiency [47].

Pump is not restricted for water-only applications. Thus, the tip-clearance effect on pump efficiency for other media is also important. Engin and Gur [48] investigated the effect of varying tip clearances on the energy performance of a pump that handles solid-liquid mixtures. They found that the flow structure is nearly the same at various ratios of pump head to tip-clearance size for different mixtures. However, increasing the solid proportion results in a stronger efficiency decline caused by the tip clearance. The observation of a rotary blood pump [49] shows that hemolysis is significantly intensified by the decreasing tip clearance from 50 to $200 \mu \mathrm{m}$. Wu et al. [50] analyzed the impact of tip clearance on hemolysis in a centrifugal ventricular assist device; the hemolysis first decreased and then increased as the tip clearance increased from 50 to $200 \mu \mathrm{m}$, and the minimum value was found at $100 \mu \mathrm{m}$. The difference between References [49] and [50] is likely due to the different impeller diameters. This discrepancy suggests that the relative size of tip clearance (i.e., the ratio of tip clearance to impeller diameter) may be the key parameter for hemolysis performance, which needs to be studied further. The above discussions also show that the operation conditions of hydraulic machineries become complicated nowadays. The influence mechanism of tip-clearance flow on the pump that handles a complex work medium is unclear, which deserves more attention in future research.

\subsection{Energy Characteristics in Hydroturbines}

Hydropower is one of the reliable and renewable sources of energy worldwide. Guaranteeing energy-conservation performance of hydroturbines is of great significance. Consequently, the effects of tip clearance on the performance of different types of hydroturbines are well documented [51-53]. Numerical studies show that the impulse turbine with a $0.25 \%$ tip clearance performs nearly the same as that without a tip clearance for all flow rates; further increasing the tip clearance can remarkably change turbine performance [51]. The Wells turbine is more sensitive to the variation of tip clearance than the impulse turbine. A wider operation range (i.e., without stalling) would benefit from an increase in tip clearance [52]. The variation trend of turbine performance is similar to that of uniform and nonuniform tip clearance. However, the same authors showed that a reasonable collocation of nonuniform tip clearance could present better overall performance in the Wells turbine (see Figure 23). In Figure $23, \bar{\eta}$ denotes the mean turbine efficiency, $\alpha_{\mathrm{s}}$ denotes the stalling angle, and $\tau_{\mathrm{c}}$ denotes the tip-clearance size. Guénette et al. [53] studied a bulb turbine and compared the turbine performance with hub clearance, with tip clearance, and without any clearance. Their results showed that hub clearance has less impact on turbine performance than tip clearance. 
The impact of tip clearance on turbine efficiency gradually reduces with the increase in unit speed (i.e., converged curves in Figure 24a), but remains significant for all guide-vane angles (i.e., parallel curves in Figure $24 b$ ). In Figure $24, N_{11}$ denotes the unit speed, $\alpha$ denotes the guide-vane angle, and $N_{11 \text { opt }}$ and $\alpha_{\text {opt }}$ denote the design unit speed and the design guide-vane angle, respectively. Therefore, $N_{11} / N_{11 \text { opt }}$ is the relative unit speed, and $\alpha-\alpha_{\text {opt }}$ is the difference between guide-vane angle and design guide-vane angle.

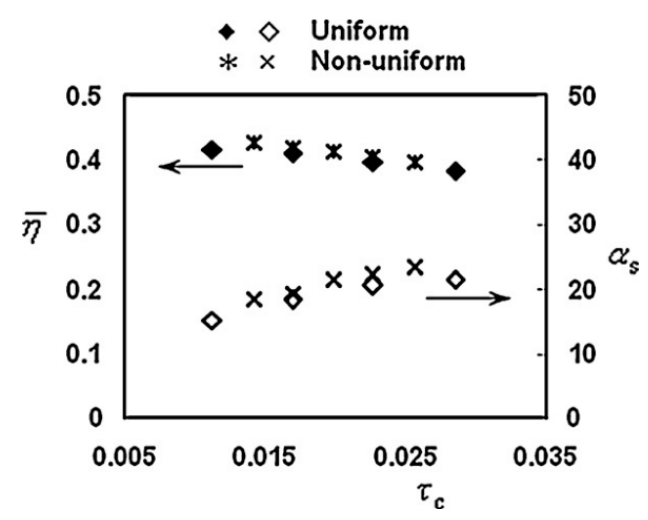

Figure 23. Comparison of mean turbine efficiency and stalling angle between the turbines with uniform and nonuniform tip clearances [52].

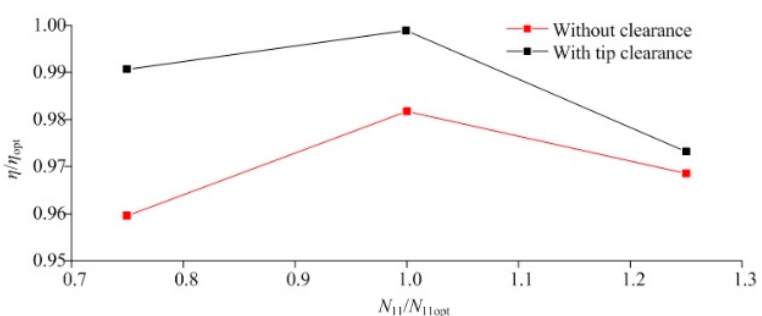

(a)

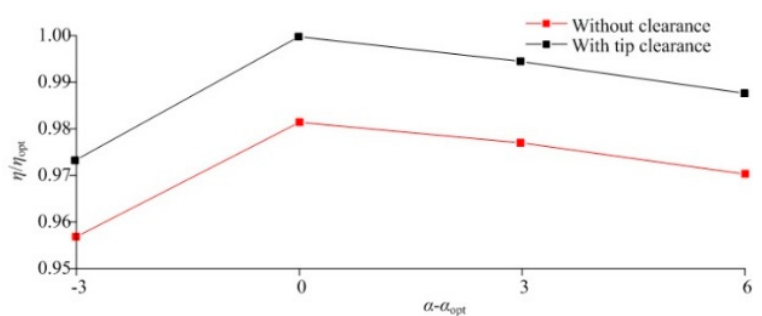

(b)

Figure 24. Comparison of efficiency of (a) $N_{11}$ (unit speed) versus (b) $\alpha$ (guide-vane angle) for turbines without clearance and with tip clearance [53].

\subsection{Energy Characteristics in Inducer of Turbopumps}

An inducer is usually installed at the upstream of the impeller to increase the inlet pressure and restrain the cavitation in the turbopump. Kim et al. $[54,55]$ numerically studied the influence of tip clearance on energy performance and head breakdown of a turbopump inducer. Their results showed that the increase in tip clearance results in a strong backflow and a rapid decline of energy performance. However, the energy loss caused by the backflow near the tip is compensated by the energy gain due to the secondary flow at the hub with the increasing tip clearance (see Figure 25). Therefore, the authors found an optimum value of tip clearance to maximize the energy performance. The cavitation cloud near the blade plays the most critical role in head breakdown, and the influence of tip-vortex cavitation and TLV cavitation is limited. This near-blade cavitation cloud decreases its thickness and increases its length with the increasing tip clearance, as shown in Figure 26. The blockage effect is intensified due to the increasing length of the cavitation cloud, and thus, a large tip clearance would contribute to head breakdown. Torre et al. [56] experimentally investigated the performance of an axial inducer with two tip-clearance sizes and showed that the cavitation behavior is significantly influenced by the tip-clearance size, especially under the breakdown condition. Before the breakdown, the increase in the head with the decrease in flow rate is intensified at a large tip clearance. Under the breakdown, an intermediate decline of the cavitation curve for a small tip clearance occurs, whereas the cavitation 
curve exhibits a continuous downward trend for a large tip clearance. The above results indicate that tip-clearance flow in an inducer leads to remarkable energy losses. The inner mechanism for these energy losses is complicated and related to tip-clearance size. The cavitation pattern induced by the tip-clearance flow presents strong spatial characteristics and a close relevance with tip-clearance size.

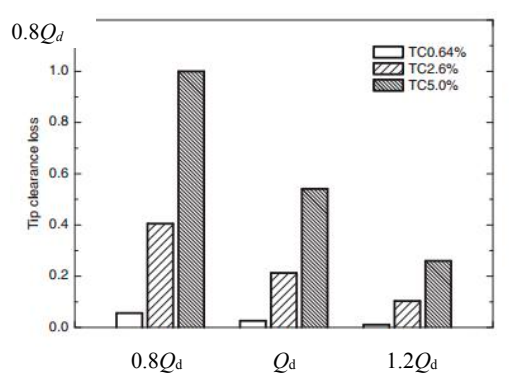

(a)

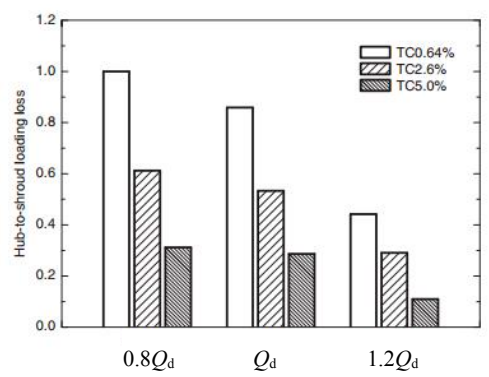

(b)

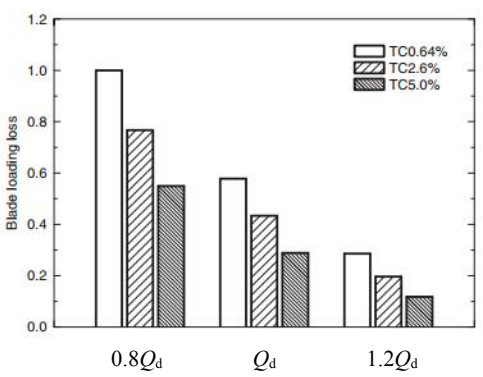

(c)

Figure 25. (a) Tip-clearance loss; (b) hub-to-shroud loading loss; (c) blade-loading loss for different tip clearances at $0.8 Q_{\mathrm{d}}, 1.0 Q_{\mathrm{d}}$, and $1.2 Q_{\mathrm{d}}[54]$.

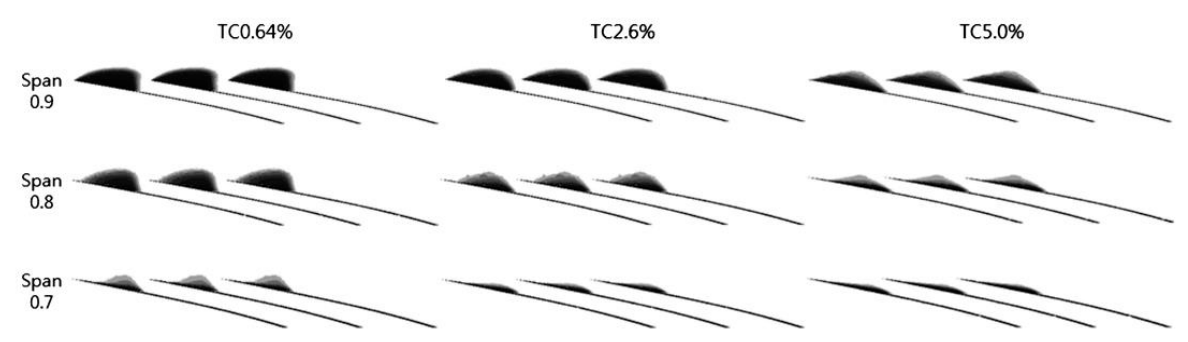

(a)

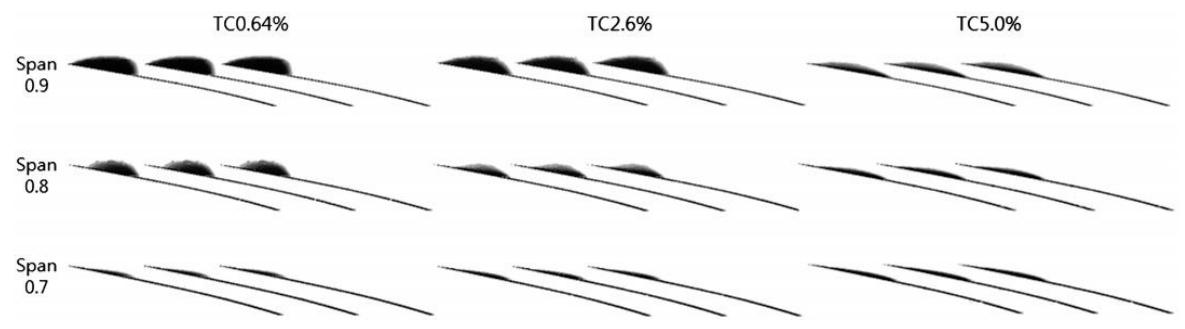

(b)

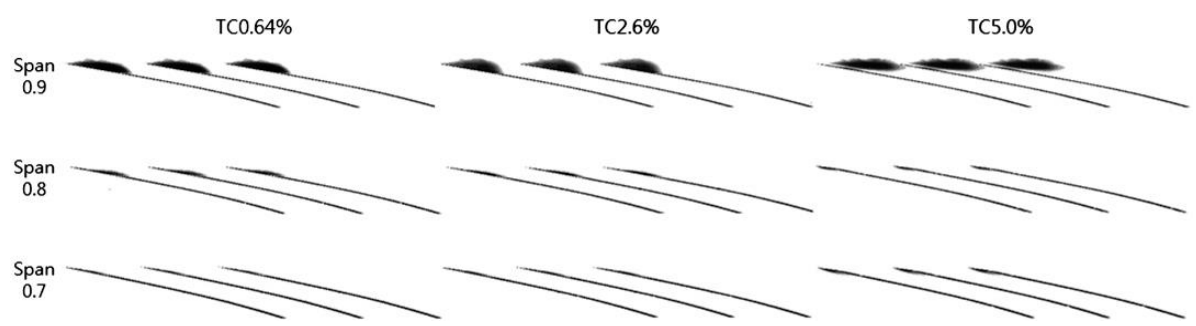

(c)

Figure 26. Cavitation pattern with different tip clearances: (a) $\sigma=0.05$ at $0.8 Q_{d} ;$ (b) $\sigma=0.05$ at $1.0 Q_{d}$; (c) $\sigma=0.07$ at $1.2 Q_{\mathrm{d}}$ [55]. Note: In Figures 25 and 26, TC is the ratio of tip clearance to radius, $Q_{\mathrm{d}}$ is the design flow rate, and $\sigma$ is cavitation number.

\subsection{Other Hydraulic Machinery Types}

Many other types of pumps and turbines have been widely applied, and the tip clearance also generates a noticeable impact on their performance. Kim and Chun [57] conducted an experiment and 
found that approximately $25 \%$ of efficiency changes is related to tip-clearance variation $(0.7 \%$ and $1.5 \%$ diameter) in an axial flow waterjet. Ding et al. [58] showed that the advance ratio, which is the ratio of rotational velocity to advancing velocity, is a major determinant of the leakage losses in a ducted propeller. In a three-blade propulsor $[59,60]$, the variation of the boundary layer in the suction pipe can significantly influence the TLV strength and core size. However, changing the Reynolds number has limited impacts. Compared with the propulsor without a tip clearance, the proportion of the primary tip vortex to the tip shed circulation decreases in the propulsor with ducted rotor, but the flow pattern near the tip seems to be more unstable. In a pump-jet propulsor [61,62], several important characteristics of the flow under the influence of the tip clearance are revealed: (1) Under the noncavitation condition, the variation trend of propulsor efficiency with the increase in the advance ratio is nearly unaffected by the tip clearance; (2) the rotational speed and the tip-clearance size have great impact on the cavitation performance curve, (3) tip-clearance flow intensifies the cavitation under a low rotational velocity; and (4) the stator blade contributes to stabilizing the flow field and decreasing the negative impact caused by tip-clearance leakage.

The above results show the significant influence of tip clearance on the energy performance of pumps and turbines, and the influencing characteristics are closely related to the machinery types. For pumps, the increase in tip clearance generally degrades hydraulic performance. For hydroturbines, an appropriate tip clearance may exist to optimize the machinery efficiency. In addition, energy performance shows different characteristics under different tip-clearance ranges and various operating conditions (e.g., unit speed and cavitation condition).

\section{Operation Stability of Pumps and Turbines with Tip Clearance}

Flow instability-induced damages are common in the operation of pumps and turbines $[63,64]$ (see examples in Figure 27). Severely unstable flows can induce significant vibrations and fatigue failures for components, especially under cavitation conditions [65-67]. To date, studies on flow instability mainly concentrate on the influence of tip-clearance flow on pressure fluctuation and radial force, as shown in the following two sections.

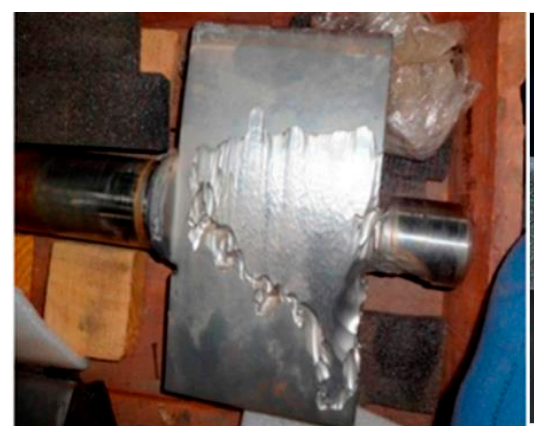

(a)

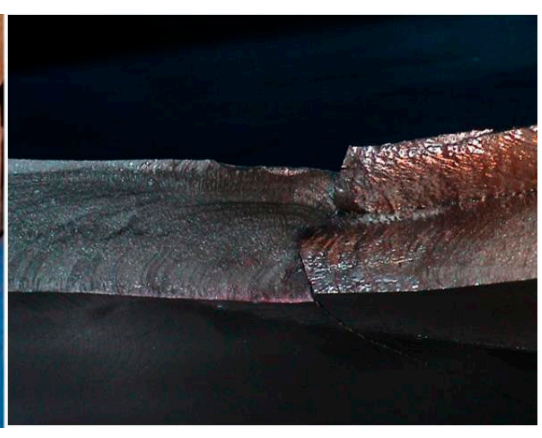

(b)

Figure 27. Damage of machinery due to pressure fluctuation: (a) Wearing plate erosion in Francis Turbine [63]; (b) crack on the runner with beach marks [64].

\subsection{Pressure Fluctuation}

Generally, pressure fluctuations in rotating machinery are mainly related to the rotor-stator interaction [68-71]. Under the tip-clearance condition, the induced leakage flow and its interaction with the main flow can lead to more complex pressure fluctuations. Feng et al. [9] found that the tip clearance intensifies the pressure fluctuations in the entire impeller region of an axial flow pump, but the pressure fluctuations in the diffuser are nearly unaffected. In a mixed-flow pump, Zhang et al. [72] found that the level of pressure fluctuation is closely related to the variation range of the tip clearance. Liu et al. [5] demonstrated that increasing the tip-clearance size from 0.0 to $1.0 \mathrm{~mm}$ significantly 
enhances the intensity of pressure fluctuations in the impeller, particularly in the tip-clearance region (see Figure 28). Meanwhile, the dominant frequency of pressure fluctuations shifts from $145 \mathrm{~Hz}$ (blade passing frequency) to $184 \mathrm{~Hz}$ due to the rising leakage flow. It is revealed that the distribution of pressure fluctuation intensity is presented as a triangular pattern under the design flow rate [43]. As shown in Figure 29, the distribution of pressure fluctuation intensity varies with the flow rate, and the influence scope of TLV on pressure fluctuation has a potential correspondence with the TLV trajectory shown in Figure 19. Torre et al. [56] measured the flow field in a three-bladed axial inducer and found that the maximum fluctuation on the blade-passage frequency decreases significantly when the tip clearance increases from 0.8 to $2 \mathrm{~mm}$. Cavitation also influences the characteristics of pressure fluctuations. $\mathrm{Xu}$ [73] found that the maximum magnitude of pressure fluctuation increases with the deteriorating cavitation induced by increasing the tip clearance in a mixed-flow pump.

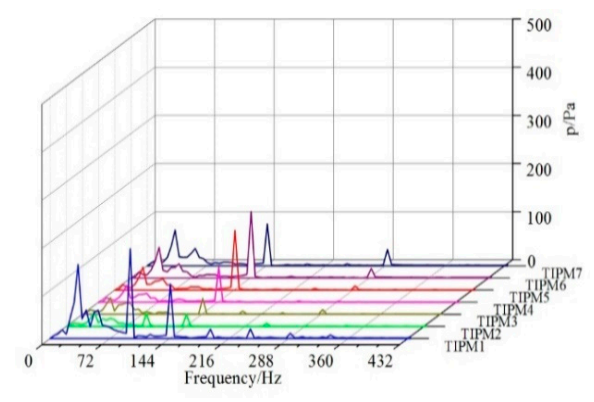

(a)

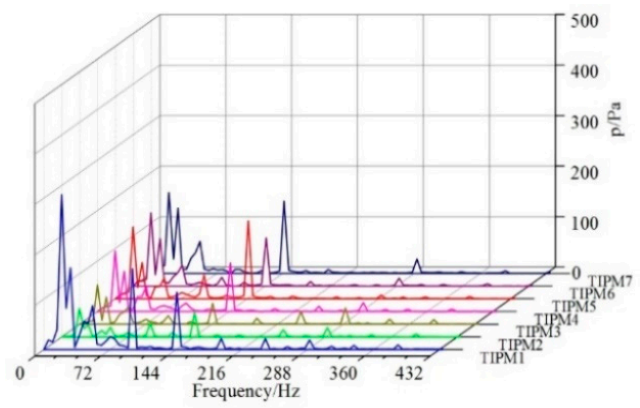

(b)

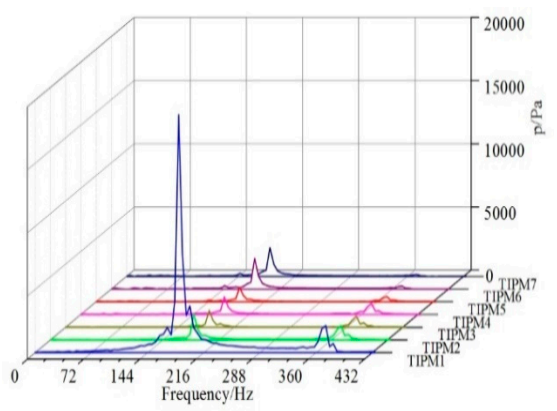

(c)

Figure 28. Spectrum of the pressure fluctuations on blade tip from leading edge to trailing edge: (a) $\delta=0.2 \mathrm{~mm}$; (b) $\delta=0.65 \mathrm{~mm}$; (c) $\delta=1.0 \mathrm{~mm}$ [2].

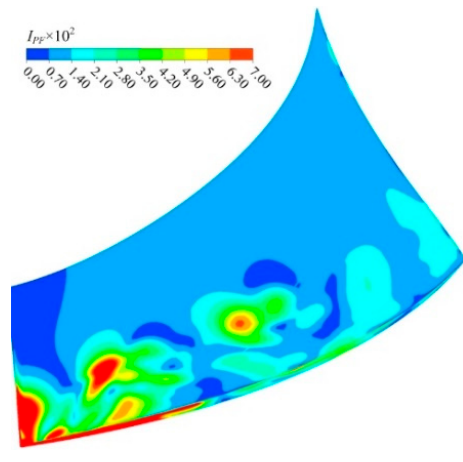

(a)

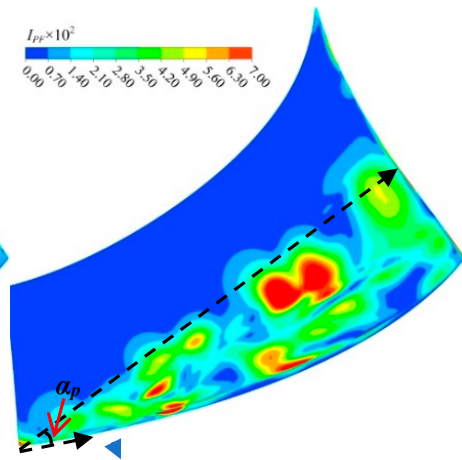

(b)

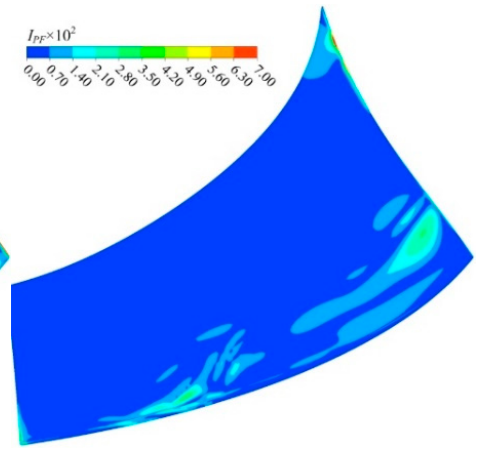

(c)

Figure 29. Distribution of pressure fluctuation intensity on pressure surface for three flow rates [40]. (a) $0.8 Q$; (b) $1.0 Q$; (c) $1.2 Q$. 
The above analyses illustrate that the influence of tip clearance on pressure fluctuation has various forms in terms of magnitude, frequency, and variation trends for different types of pumps and turbines, and the variation of the impact is due to the complex flow pattern in those divers machineries.

\subsection{Radial Force}

The unsteady flow in the impeller induces an inhomogeneous radial force and then causes vibration of the principal axis. Rotor-stator interaction $[74,75]$ is the main factor of radial force, but the tip clearance and its induced unsteady flow can also affect the characteristics of radial force. Hao $[6,76]$ studied the radial force in a mixed-flow pump with symmetrical and asymmetrical tip clearances: the radial force trajectory on the principle axis is enclosed, consisting of six individual ellipses due to the rotor-stator interaction (six guide vanes), as shown in Figure 30. Asymmetrical tip clearances cause a significant offset of the trajectory center, and the average radial force increases sharply. The dominant frequency amplitude varies only slightly for different tip-clearance sizes under the symmetrical condition, but it dramatically increases under the asymmetrical condition (see Figure 31). Moreover, the asymmetrical tip clearance deteriorates the cavitation performance of the pump [6]. Consequently, the amplitude of radial force increases because of the cavitation deterioration, and the direction of radial force also changes due to the unsymmetrical distribution of the cavitation region.

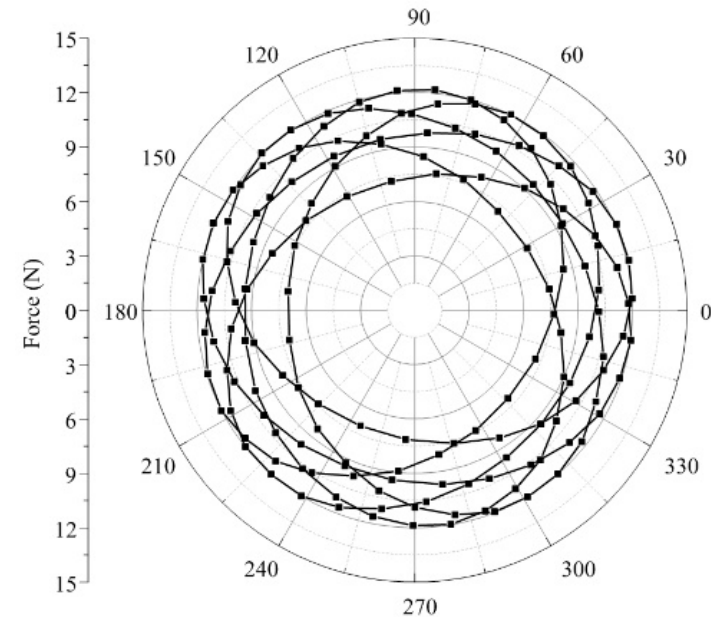

(a)

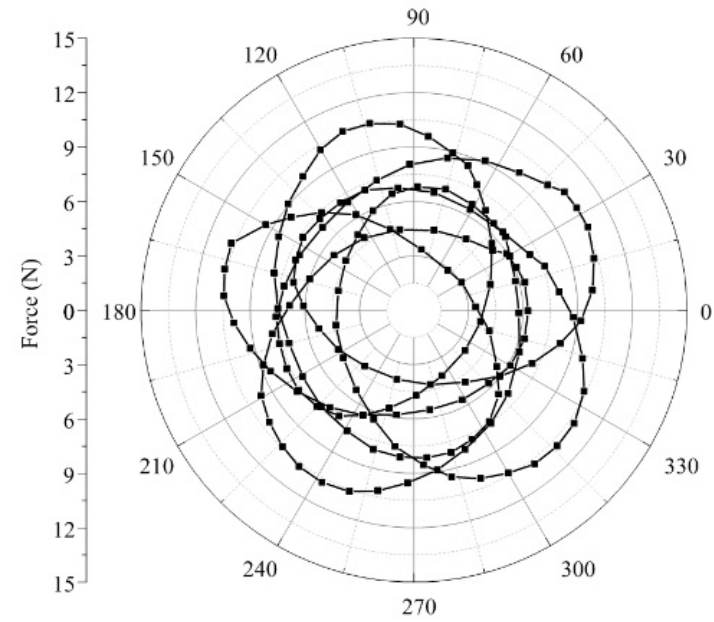

(c)

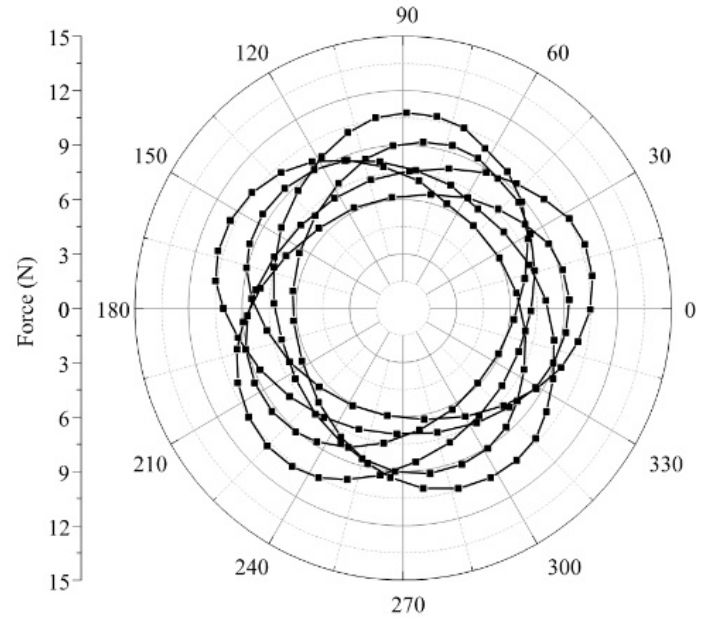

(b)

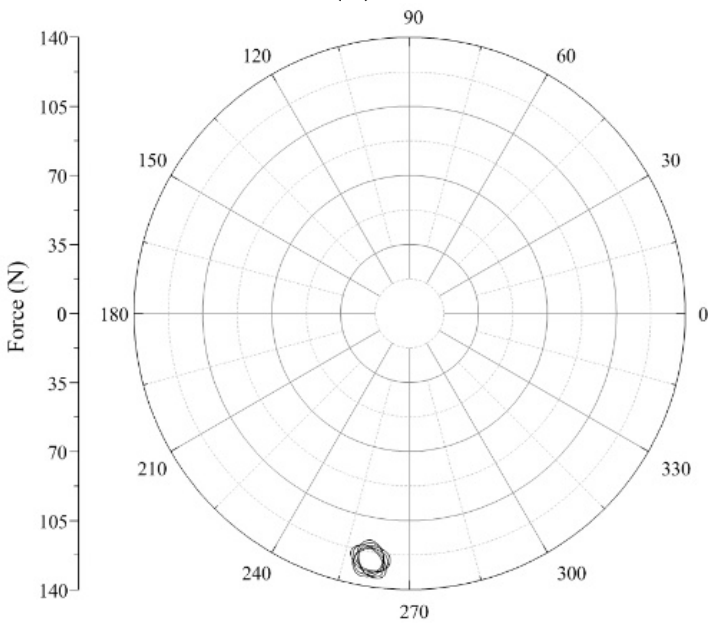

(d)

Figure 30. Radial force trajectory on principle axis for different tip clearances: (a) $0 \mathrm{~mm} \times 5$; (b) $1 \mathrm{~mm} \times 5$; (c) $2 \mathrm{~mm} \times 5$; (d) $1 \mathrm{~mm} \times 4+2 \mathrm{~mm} \times 1$ [76]. 


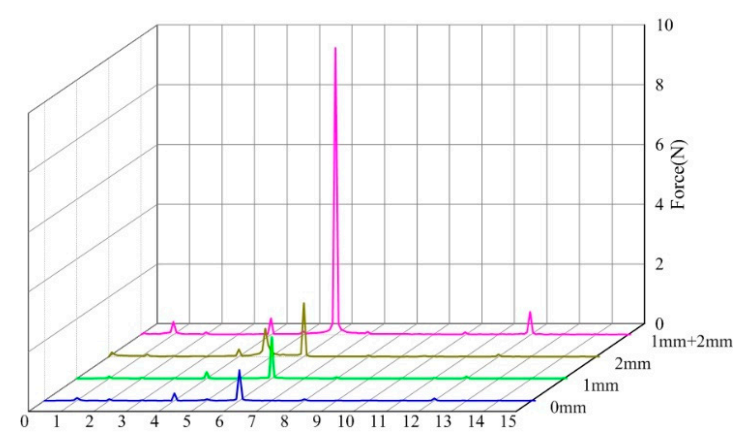

Figure 31. Spectrum of radial force for different tip clearances [76].

Despite the abovementioned achievements, the impact of tip clearance on pressure fluctuation and radial force is still not fully understood. For instance, the evolution mechanism of vibration and the corresponding optimization scheme are still unidentified, and how the amplitude and dominant frequency vary symmetrically under the influence of tip-clearance flow remains unclear. Further investigations are needed to address these issues.

\section{Key Parameters and Optimization}

The above review demonstrates the influence of the tip clearance on flow pattern, and particularly the energy performance deterioration due to the induced tip-leakage flow. These studies provide valuable information for engineering optimization. To maximize energy performance, various influence parameters on the tip-clearance flow need to be evaluated to assist the optimization of the flow pattern in pump and turbine. This section also lists several optimization methods that have been proposed in recent years to suppress TLV and the associated cavitation, further increasing the performance.

\subsection{Tip-Clearance Size}

Previous studies have shown that the influence of tip-clearance size on energy performance and flow pattern is complicated and is closely related to machinery types, operation conditions, and other factors. For pumps, the increase in tip clearance usually deteriorates energy performance. However, for hydroturbines, an appropriate tip clearance to optimize overall efficiency may exist. Moreover, the impact of tip-clearance size on the TLV and associated cavitation varies in different tip-clearance ranges.

The influence of the tip-clearance size on cavitation behavior is not universally determined. Gopalan et al. [77] found that decreasing the tip-clearance size intensifies the TLV and promotes the occurrence of cavitation. By contrast, Boulon et al. [12] concluded that the decrease in tip clearance can reduce the cavitation-cloud size near the hydrofoil if the tip clearance is below $4 \mathrm{~mm}$. Numerical results for a mixed-flow pump [73] show that increasing the tip-clearance size can increase the TLV strength and the critical-cavitation number, which exacerbates the cavitation (see Table 4 for parameters). NPSHC is the critical net positive suction head. It can be inferred that the discrepancy of these findings is due to the rotational motion of the impeller in the pump and the different ranges of the tip clearance being investigated.

Table 4. Head and NPSHC (critical net positive suction head) values of pump with different tip clearances [73].

\begin{tabular}{ccc}
\hline Tip-Clearance Size $(\mathbf{m m})$ & Head $(\mathbf{m})$ & NPSHC $(\mathbf{m})$ \\
\hline 0.0 & 17.34 & 13.58 \\
0.2 & 16.73 & 13.67 \\
0.65 & 16.00 & 13.95 \\
1.0 & 15.46 & 14.23 \\
\hline
\end{tabular}




\subsection{Tip Shape}

Tip shape is another crucial parameter of tip-clearance flow. Guo et al. [78] investigated the influence of tip shape (a round tip and a sharp tip) on the flow pattern near a hydrofoil under different attack angles and tip clearances, extending the experimental work of Dreyer et al. [11,12]. As shown in Figure 32, the energy losses caused by the TLV decrease under the sharp-tip condition, but the tip-separation vortex (TSV) increases considerably near the blade tip, thereby resulting in more separation losses of energy than those under the round tip condition. The trade-off between TLV and TSV under the sharp-tip condition decreases the cavitation on the blade surface, but the pressure drop in the tip-clearance region intensifies the cavitation on the blade tip. Wu et al. [79] focused on the TLV cavitation cloud in an axial-flow pump with different blade-tip-rounding methods. They observed that optimized pump performance is obtained by using twice tip rounding. This conclusion is consistent with the finding of You et al. [36-38] (see Section 3), which demonstrates the optimization of the system with appropriate tip shapes.

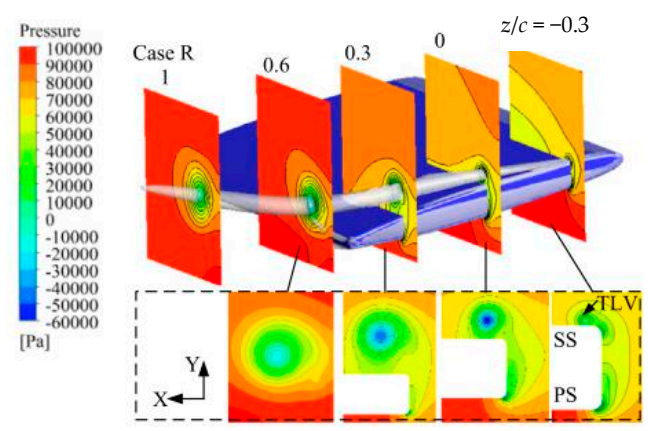

(a)

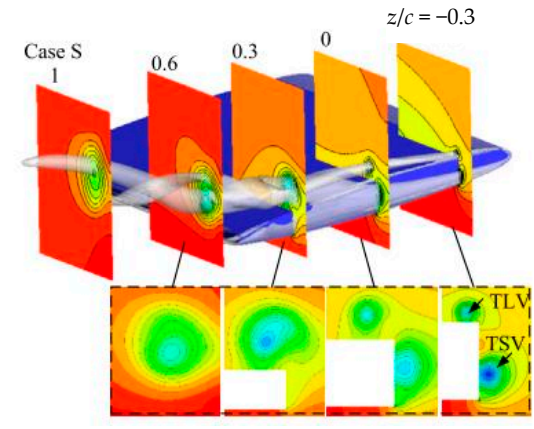

(b)

Figure 32. Pressure distribution on different chord sections: (a) round-tip foil; (b) sharp-tip foil [78]. TSV: tip-separation vortex.

Tip thickening is another method for improving the flow pattern near the tip clearance. Mei and Zhou [80] studied the effect of tip thickening in a ducted propeller. Their numerical results show that a thick-tip foil remarkably reduces the strength of TLV, and the pressure drop in the TLV core on the middle chord section is reduced by approximately $33 \%$ from that of the original propeller. A T-shape blade tip [81], as shown in Figure 33, was proposed to improve the performance of a mixed-flow pump. It is indicated that this tip pattern can also improve pump efficiency by $1.86 \%$ and reduce leakage flow rate by $15.95 \%$.

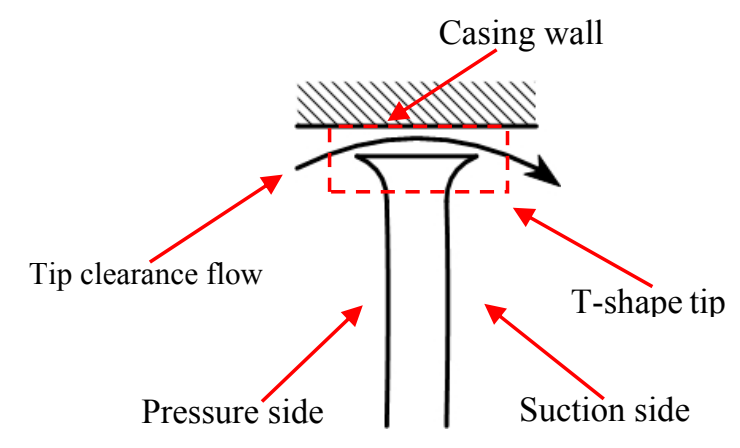

Figure 33. Sketch of T-shape blade tip [81].

Inspired by work on TLV suppression for gas turbines, compressors, and fans, Liu et al. [82] first proposed an advanced C-groove method to suppress the TLV and further improve the energy 
performance of a hydrofoil in tidal energy, as shown in Figure 34. Their results show that the proposed C-groove successfully suppresses the primary TLV in its inception stage by groove-jet impingement and weakens the secondary TLV by the groove-channel flow, which is illustrated in Figure 35 . With the application of the C-groove method, the decrease in vortex volume reaches $67.94 \%$, while the lift-drag ratio performance is also improved by a maximum of $2.79 \%$.

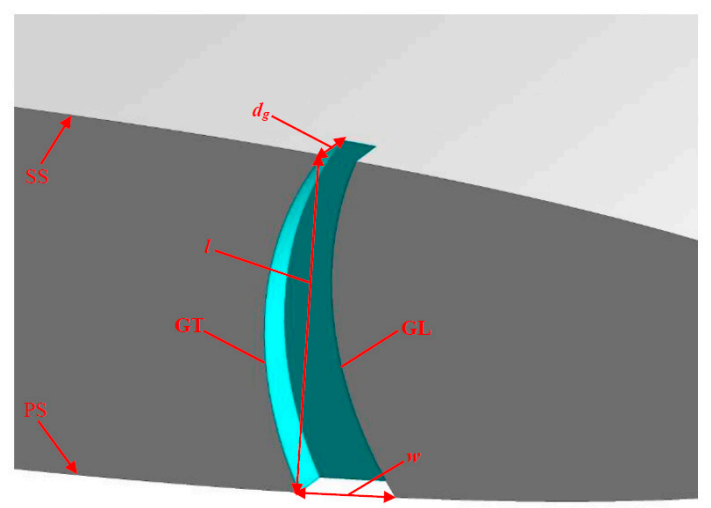

Figure 34. Sketch map of C groove on blade tip [82]. GT: groove leading edge; GL: groove trailing edge.

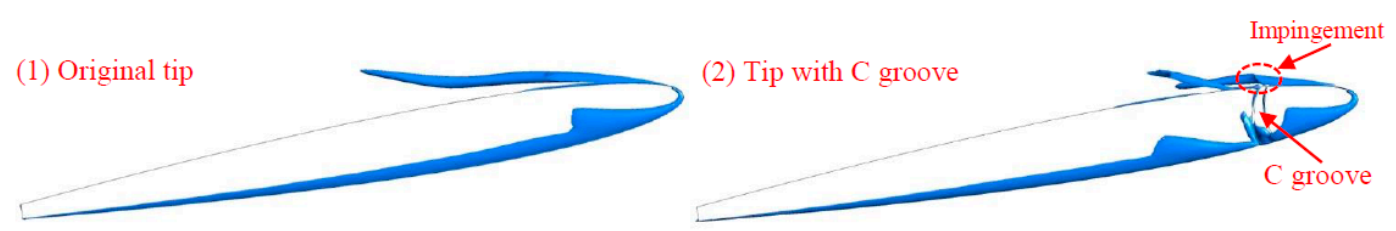

(a)

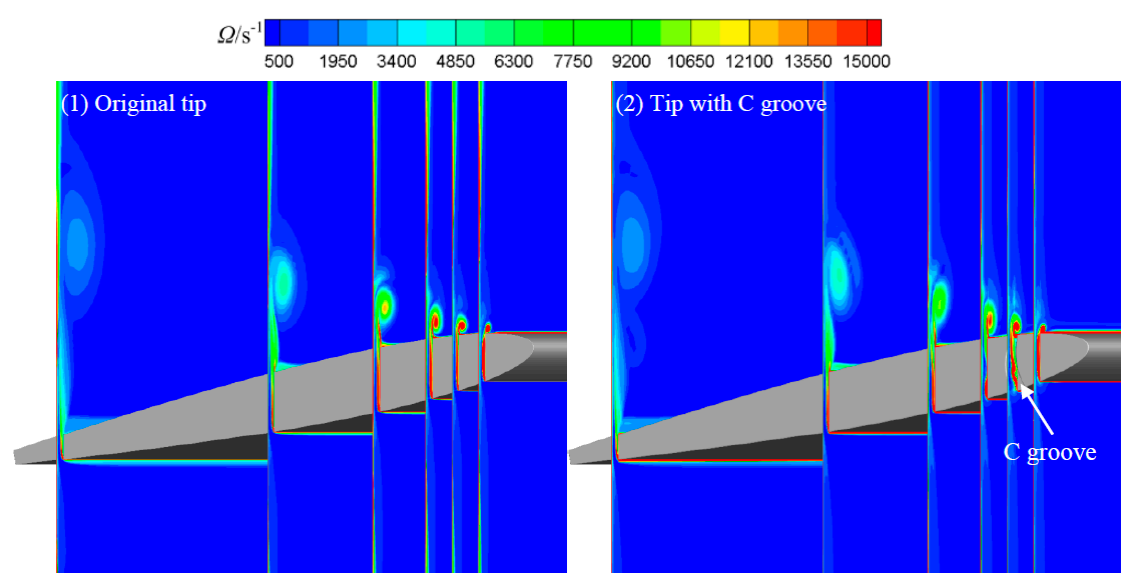

(b)

Figure 35. Suppression effect of C-groove method on TLV [82]. (a) Vortex defined by $Q$ criterion $\left(Q=3 \times 10^{7} \mathrm{~s}^{-1}\right) ;(\mathbf{b})$ vorticity magnitude on six streamwise planes.

Schemes for modifying the tip shape to suppress TLV cavitation have been reported based on experimental and numerical studies [83,84]. Roussopoulos and Monkewitz [83] studied the flow field in a model Kaplan turbine blade using different anticavitation lips. Their results suggest that a new leakage vortex occurs at the lip-leading edge when the lip size exceeds the separation line (see Figure 36), which moves the vortex away from the blade. Nevertheless, cavitation likely occurs in the closing-gap region, which may cast doubt on the optimization effect of large lip sizes. Experiments in a shrouded underwater propulsor indicate that the configuration of a convergent 
gap can better optimize the cavitation performance compared with other tested gap configurations (see Reference [84] for details).

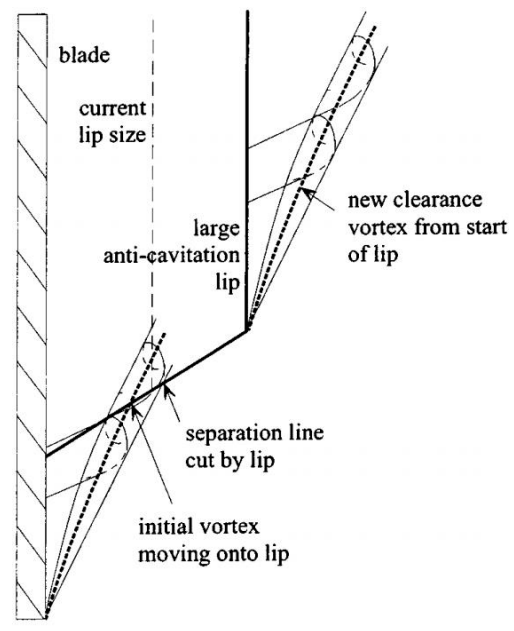

Figure 36. Sketch of leakage vortex with a large anticavitation lip [83].

\subsection{Other Parameters and Optimization Methods}

In applications, the work conditions of pumps and turbines are complex. Consequently, new demands and new means to suppress TLV and associated unstable behaviors exist. The impact of tip clearance on pump performance in the multiphase condition is more complicated than that in single-phase fluid, and the main reason is the property variation of the working medium. Yang et al. [85] studied the effect of inlet gas volume fractions (IGVFs) on the leakage losses in a synchronal rotary multiphase pump. Their result shows that the increase in IGVFs changes the properties (e.g., average viscosity and density) of the working medium and further enlarges the leakage flow rate. They concluded that both leakage loss and friction loss must be taken into account under the multiphase condition to optimize the scheme of the rotor and cylinder.

Various optimization strategies have been proposed to suppress the TLV cavitation and operation instability [86,87]. Mass injection of water and aqueous polymer solutions are used to suppress the cavitation inception. Ganesh et al. [86] studied the effect of mass injection on the tip vortex cavitation near an elliptical hydrofoil. Their PIV measurements show that mass injection into the rollup region of the tip-vortex cavitation decreases the flow instability in the tip-vortex core region and enlarges the core size, which further suppresses the cavitation inception. Rivetti et al. [87] investigated the pressurized-air injection in a Kaplan turbine model. Their results show that at the cost of slight reduction in efficiency, air injection successfully decreases the fluid force driven by the guide vanes and weakens the operation vibration. As a result, it may effectively relief the erosion due to tip-leakage cavitation.

To summarize, the major factors of pump and turbine performance with tip clearance are tip-clearance size, blade-tip rounding, and blade-tip foil thickening. Table 5 lists several optimization strategies and the corresponding optimization effects in different machineries. Despite promising progress, a universal optimization scheme about tip-clearance impact has not been reached, and most of the optimizations are individual approaches, which are not systematically connected to the previous studies of the flow mechanism. In addition, a comprehensive understanding of performance optimization has not been established when multiple variables are present. How these factors are connected and, in turn, influence overall machinery performance must be subjected to further research. 
Table 5. Optimization strategies and corresponding optimization effects.

\begin{tabular}{|c|c|c|}
\hline Optimization Scheme & Machinery Type & Conclusion \\
\hline Round tip and sharp tip & Hydrofoil [78] & $\begin{array}{l}\text { Sharp tip decreases TLV and round tip } \\
\text { decreases TSV }\end{array}$ \\
\hline Blade-tip rounding & Axial-flow pump [79] & $\begin{array}{l}\text { twice tip rounding is optimal to the } \\
\text { pump performance }\end{array}$ \\
\hline Blade-tip thickening & Ducted propeller [80] & $\begin{array}{l}\text { Both the strength of TLV and pressure } \\
\text { drop in the TLV core on the middle } \\
\text { chord section are reduced }\end{array}$ \\
\hline T-shape tip & mixed-flow pump [81] & $\begin{array}{l}\text { This tip shape can improve pump } \\
\text { efficiency by } 1.86 \% \text { and reduce leakage } \\
\text { flow rate by } 15.95 \%\end{array}$ \\
\hline C groove & Hydrofoil [82] & $\begin{array}{l}\text { C groove maximally suppresses } \\
\text { tip-leakage vortex by } 67.94 \% \text {, and } \\
\text { improves energy performance by } 2.79 \% \text {. }\end{array}$ \\
\hline Anticavitation lip & Kaplan turbine [83] & $\begin{array}{l}\text { Large lip can suppress cavitation on the } \\
\text { blade, but may intensify cavitation in } \\
\text { the closing-gap region }\end{array}$ \\
\hline Gap configuration & Underwater propulsors [84] & $\begin{array}{l}\text { Convergent gap shows the best } \\
\text { cavitation performance }\end{array}$ \\
\hline Mass injection & Hydrofoil [86] & $\begin{array}{l}\text { Flow instability in the tip-vortex core } \\
\text { region is decreased and cavitation } \\
\text { inception is suppressed. }\end{array}$ \\
\hline Pressurized-air injection & Kaplan turbine [87] & $\begin{array}{l}\text { The fluid force driven by the guide } \\
\text { vanes is decreased and the operation } \\
\text { vibration is weakened }\end{array}$ \\
\hline
\end{tabular}

\section{Conclusions}

This review paper focuses on the influence of tip clearance on the flow mechanism, energy performance, and operation stability. The effect factors and optimization methods in various types of propellers, pumps and turbines are also investigated. The main conclusions drawn from existing research are summarized as follows:

(1) The flow mechanism in the tip-clearance region is well documented. In this review, the temporal and spatial evolution of various vortices (i.e., tip-leakage vortex, tip-separation vortex, and cavitation vortex), the features of vortex trajectory, and the triangle shape of the vortex are clearly identified.

(2) Tip clearance has considerable influence on the energy performance of all types of pumps and turbines. The influence characteristics are closely related to the machinery type.

(3) The TLV and the associated cavitation induce serious flow instability. The domain frequency, amplitude of pressure fluctuation, and radial force are influenced by tip-clearance size, the symmetry of the clearance, and operation conditions.

(4) Tip-clearance size and tip shape are crucial parameters for flow characteristics in the tip-clearance region. Blade-tip rounding, blade-tip foil thickening and grooved tip have positive effects on suppressing the tip-leakage vortex and improving machine performance. Anticavitation lip, water injection, and pressurized-air injection are effective means to restrict TLV cavitation and operation instability.

On the basis of the above results and discussion, the understanding and prospects on future research lines are proposed as follows:

(1) Given the advance knowledge on the flow characteristics induced by tip clearance, a recurring challenge is how to connect the fundamental fluid dynamics to the optimization design parameters. 
Although various optimization strategies from the literature have been demonstrated, most schemes are still restricted to limited applications. The reason is that there is a lack of systematic investigations on the relationship between the flow pattern with the external characteristics of pumps and turbines.

(2) Interdisciplinary communication is important and urgent. The related works on suppressing tip-clearance flow in other machineries, such as gas turbines and fans, can be referenced and further developed in pumps and turbines, especially on flow-control means.

(3) Cavitation has a strong impact on machine-operation performance, vibration, and noise. Under the influence of tip clearance, cavitation interacting with the tip-clearance flow becomes more complicated. Hence, cavitation induced by tip clearance and its suppression deserve more attention in future work.

(4) With the development of new energy and machinery types, including pumped storage power, tidal power, and ventricular blood pump, there are new demands to conduct research on tip clearance in complicated operation conditions, such as two-direction transient flow, tidal flow, and microscale blood flow.

Author Contributions: Y.L. and L.T. conceived and designed the experiments and simulations; Y.L. and L.T. performed the experiments and simulations; Y.L., L.T. and B.W. analyzed the data and wrote the paper.

Funding: This research was funded by the National Natural Science Foundation of China (Grant numbers 51741906, 51809148), the State Key Laboratory of Hydroscience and Engineering (Grant number 2018-KY-02), the Open Research Fund Program of State Key Laboratory of Hydroscience and Engineering (Grant number sklhse-2018-E-01), the Key Laboratory of Fluid and Power Machinery (Xihua University), and the Ministry of Education (Grant number szjj-2017-100-1-004).

Acknowledgments: This work has been supported by the National Natural Science Foundation of China (Grant numbers 51741906, 51809148), the State Key Laboratory of Hydroscience and Engineering (Grant number 2018-KY-02), the Open Research Fund Program of State Key Laboratory of Hydroscience and Engineering (Grant number sklhse-2018-E-01), the Key Laboratory of Fluid and Power Machinery (Xihua University), and the Ministry of Education (Grant number szjj-2017-100-1-004).

Conflicts of Interest: The authors declare no conflict of interest.

\section{References}

1. Amponsah, N.Y.; Troldborg, M.; Kington, B.; Aalders, I.; Hough, R.L. Greenhouse gas emissions from renewable energy sources: A review of lifecycle considerations. Renew. Sustain. Energy Rev. 2014, 39, 461-475. [CrossRef]

2. Pérez-Sánchez, M.; Sánchez-Romero, F.J.; Ramos, H.M.; López-Jiménez, P.A. Energy recovery in existing water networks: Towards greater sustainability. Water 2017, 9, 97. [CrossRef]

3. Coelho, B.; Andrade-Campos, A. Efficiency achievement in water supply systems-A review. Renew. Sustain. Energy Rev. 2014, 30, 59-84. [CrossRef]

4. Laborde, R.; Chantrel, P.; Mory, M. Tip clearance and tip vortex cavitation in an axial flow pump. J. Fluids Eng. 1997, 119, 680-685. [CrossRef]

5. Liu, Y.; Tan, L.; Hao, Y.; Xu, Y. Energy performance and flow patterns of a mixed-flow pump with different tip clearance sizes. Energies 2017, 10, 191. [CrossRef]

6. Hao, Y.; Tan, L. Symmetrical and unsymmetrical tip clearances on cavitation performance and radial force of a mixed flow pump as turbine at pump mode. Renew. Energy 2018, 127, 368-376. [CrossRef]

7. Goto, A. The effect of tip leakage flow on part-load performance of a mixed-flow pump impeller. J. Turbomach. 1992, 114, 383-391. [CrossRef]

8. Zhang, D.; Shi, W.; Pan, D.; Dubuisson, M. Numerical and experimental investigation of tip leakage vortex cavitation patterns and mechanisms in an axial flow pump. J. Fluids Eng. 2015, 137, 121103-121114. [CrossRef]

9. Feng, J.; Luo, X.; Guo, P.; Wu, G. Influence of tip clearance on pressure fluctuations in an axial flow pump. J. Mech. Sci. Technol. 2016, 30, 1603-1610. [CrossRef]

10. Maines, B.H.; Arndt, R.A. Tip vortex formation and cavitation. J. Fluids Eng. 1997, 119, 413-419. [CrossRef]

11. Higashi, S.; Yoshida, Y.; Tsujimoto, Y. Tip leakage vortex cavitation from the tip clearance of a single hydrofoil. JSME Int. J. 2002, 45, 662-671. [CrossRef] 
12. Boulon, O.; Callenaere, M.; Franc, J.P.; Michel, J.-M. An experimental insight into the effect of confinement on tip vortex cavitation of an elliptical hydrofoil. J. Fluid Mech. 1999, 390, 1-23. [CrossRef]

13. Murayama, M.; Yoshida, Y.; Tsujimoto, Y. Unsteady tip leakage vortex cavitation originating from the tip clearance of an oscillating hydrofoil. J. Fluids Eng. 2006, 128, 421-429. [CrossRef]

14. Dreyer, M.; Decaix, J.; Münch-Alligné, C.; Farhat, M. Mind the gap: A new insight into the tip leakage vortex using stereo-PIV. Exp. Fluids 2014, 55, 1-13. [CrossRef]

15. Dreyer, M.; Decaix, J.; Münch-Alligné, C.; Farhat, M. Mind the gap-tip leakage vortex in axial turbines. In Proceedings of the 27th IAHR Symposium on Hydraulic Machinery and Systems (IHAR 2014), Montreal, QC, Canada, 22-26 September 2014.

16. Miorini, R.L.; Wu, H.; Katz, J. The inner structure and turbulent evolution of the tip leakage vortex in an axial pump: Part I: Instantaneous results. In Proceedings of the ASME Fluids Engineering Division Summer Conference 2009 (FEDSM 2009), Vail, CO, USA, 2-6 August 2009.

17. Wu, H.; Miorini, R.L.; Katz, J. Measurements of the tip leakage vortex structures and turbulence in the meridional plane of an axial water-jet pump. Exp. Fluids 2011, 50, 989-1003. [CrossRef]

18. Miorini, R.L.; Wu, H.; Katz, J. The internal structure of the tip leakage vortex within the rotor of an axial waterjet pump. J. Turbomach. 2012, 134, 031018. [CrossRef]

19. Wu, H.; Miorini, R.L.; Tan, D.; Katz, J. Turbulence within the tip-leakage vortex of an axial waterjet pump. AIAA J. 2012, 50, 2574-2587. [CrossRef]

20. Wu, H.; Tan, D.; Miorini, R.L.; Katz, J. Three-dimensional flow structures and associated turbulence in the tip region of a waterjet pump rotor blade. Exp. Fluids 2011, 51, 1721-1737. [CrossRef]

21. Miorini, R.L.; Wu, H.; Tan, D.; Katz, J. Three-dimensional structure and turbulence within the tip leakage vortex of an axial waterjet pump. In Proceedings of the ASME-JSME-KSME Joint Fluids Engineering Conference 2011 (AJK, 2011), Shizuoka, Japan, 24-29 July 2011; pp. 271-281.

22. Tan, D.; Miorini, R.L.; Keller, J.; Katz, J. Flow visualization using cavitation within blade passage of an axial waterjet pump rotor. In Proceedings of the ASME Fluids Engineering Division Summer Meeting 2012 (FEDSM 2012), Puerto Rico, USA, 8-12 July 2012; pp. 395-404.

23. Tan, L.; Zhu, B.; Cao, S.; Wang, Y. Cavitation flow simulation for a centrifugal pump at a low flow rate. Chin. Sci. Bull. 2013, 58, 949-952. [CrossRef]

24. Tan, D.; Li, Y.; Wilkes, I.; Vagnoni, E.; Miorini, R.L.; Katz, J. Experimental investigation of the role of large scale cavitating vortical structures in performance breakdown of an axial waterjet pump. J. Fluids Eng. 2015, 137, 317-320. [CrossRef]

25. Yang, C.; Chen, C.; Wang, J.; Ji, Q. Three-dimensional viscous numerical simulation of tip clearance flow in axial-flow pump. J. Therm. Sci. 2003, 12, 231-233. [CrossRef]

26. Hah, C. Investigation of turbulent tip leakage vortex in an axial water jet pump with large eddy simulation. In Proceedings of the ASME Fluids Engineering Division Summer Meeting 2012 (FEDSM 2012), Puerto Rico, USA, 8-12 July 2012; pp. 135-142.

27. Masuda, N.; Austen, F.; Maeda, H. The effect of tip leakage vortex on cavitation performance in axial hydro turbine. In Proceedings of the ASME-JSME-KSME Joint Fluids Engineering Conference 2015 (AJKFluids 2015), Seoul, Korea, 26-31 July 2015.

28. Flaszyński, P.; Szantyr, J.A.; Biernacki, R.; Dymarski, P.; Kraskowski, M. A method for the accurate numerical prediction of the tip vortices shed from hydrofoils. Pol. Marit. Res. 2010, 17, 10-17.

29. Decaix, J.; Dreyer, M.; Balarac, G.; Farhatb, M.; Müncha, C. RANS computations of a confined cavitating tip-leakage vortex. Eur. J. Mech. B Fluids 2017, 67, 198-210. [CrossRef]

30. Szantyr, J.; Flaszyński, P.; Tesch, K.; Suchecki, W.; Alabrudziński, S. An experimental and numerical study of tip vortex cavitation. Pol. Marit. Res. 2012, 18, 14-22. [CrossRef]

31. Decaix, J.; Balarac, G.; Dreyer, M.; Münch, C. RANS and LES computations of the tip-leakage vortex for different gap widths. J. Turbul. 2015, 16, 309-341. [CrossRef]

32. Decaix, J.; Balarac, G.; Dreyer, M. RANS computations of tip vortex cavitation. In Proceedings of the 9th International Symposium on Cavitation (CAV 2015), Lausanne, Switzerland, 6-10 December 2015.

33. Guo, Q.; Zhou, L.; Wang, Z.; Liua, M.; Cheng, H. Numerical simulation for the tip leakage vortex cavitation. Ocean Eng. 2018, 151, 71-81. [CrossRef]

34. You, D.; Mittal, R.; Wang, M.; Moin, P. Computational methodology for large-eddy simulation of tip-clearance flows. AIAA J. 2003, 42, 271-279. [CrossRef] 
35. You, D.; Mittal, R.; Wang, M.; Moin, P. Large-eddy simulation of a rotor tip-clearance flow. In Proceedings of the 40th AIAA Aerospace Sciences Meeting \& Exhibit (AIAA 2002), Reno, NV, USA, 14-17 January 2002.

36. You, D.; Wang, M.; Moin, P. Study of tip-clearance flow in turbomachines using large-eddy simulation. Comput. Sci. Eng. 2004, 6, 38-46.

37. You, D.; Wang, M.; Moin, P.; Mittal, R. Prediction and analysis of rotor tip-clearance flows using large-eddy simulation. In Proceedings of the Users Group Conference 2004 (DOD_UGC 2004), Washington, DC, USA, 7-11 June 2004; pp. 174-181.

38. Moin, P.; Wang, M.; You, D.; Mittal, R. Large-eddy simulation of rotor tip-clearance flows: Computational challenges and accomplishments. In Proceedings of the Users Group Conference 2005 (DOD_UGC 2005), Washington, DC, USA, 27-30 June 2005; pp. 134-141.

39. You, D.; Wang, M.; Moin, P.; Mittal, R. Large-eddy simulation analysis of mechanisms for viscous losses in a turbomachinery tip-clearance flow. J. Fluid Mech. 2007, 586, 177-204. [CrossRef]

40. You, D.; Wang, M.; Moin, P.; Mittal, R. Vortex dynamics and mechanisms for viscous losses in the tip-clearance flow. In Proceedings of the ASME Fluids Engineering Division Summer Meeting 2005 (FEDSM 2005), Houston, TX, USA, 19-23 June 2005; pp. 1601-1610.

41. You, D.; Wang, M.; Moin, P.; Mittal, R. Vortex dynamics and low-pressure fluctuations in the tip-clearance flow. J. Fluids Eng. 2007, 129, 1002-1014. [CrossRef]

42. Zhang, D.; Shi, W.; van Esch, B.P.M.; Shi, L.; Dubuisson, M. Numerical and experimental investigation of tip leakage vortex trajectory and dynamics in an axial flow pump. Comput. Fluids 2015, 112, 61-71. [CrossRef]

43. Liu, Y.; Tan, L. Tip clearance on pressure fluctuation intensity and vortex characteristic of a mixed flow pump as turbine at pump mode. Renew. Energy 2018, 129, 606-615. [CrossRef]

44. Zhang, D.; Shi, L.; Shi, W.; Zhao, R.; Wang, H.; van Esch, B.P.M. Numerical analysis of unsteady tip leakage vortex cavitation cloud and unstable suction-side-perpendicular cavitating vortices in an axial flow pump. Int. J. Multiph. Flow 2015, 77, 244-259. [CrossRef]

45. Okita, K.; Ugajin, H.; Matsumoto, Y. Numerical analysis of the influence of the tip clearance flows on the unsteady cavitating flows in a three-dimensional inducer. J. Hydrodyn. 2009, 21, 34-40. [CrossRef]

46. Saha, T.K.; Soundranayagam, S. Performance of a mixed flow pump with varying tip clearance: Part 1. Proc. Inst. Mech. Eng. Part A J. Power Energy 1996, 210, 305-318. [CrossRef]

47. Soundranayagam, S.; Saha, T.K. Performance of a mixed flow pump with varying tip clearance: Part 2. Proc. Inst. Mech. Eng. Part A J. Power Energy 1996, 210, 319-327. [CrossRef]

48. Engin, T.; Gur, M. Performance characteristics of a centrifugal pump impeller with running tip clearance pumping solid-liquid mixtures. J. Fluids Eng. Trans. ASME 2001, 123, 532-538. [CrossRef]

49. Kim, N.J.; Diao, C.; Ahn, K.H.; Lee, S.J.; Kameneva, M.V.; Antaki, J.F. Parametric study of blade tip clearance, flow rate, and impeller speed on blood damage in rotary blood pump. Artif. Organs 2009, 33, 468-474. [CrossRef] [PubMed]

50. Wu, J.; Paden, B.E.; Borovetz, H.S.; Antaki, J.F. Computational fluid dynamics analysis of blade tip clearances on hemodynamic performance and blood damage in a centrifugal ventricular assist device. Artif. Organs 2010, 34, 402-411. [CrossRef] [PubMed]

51. Thakker, A.; Dhanasekaran, T.S. Computed effects of tip clearance on performance of impulse turbine for wave energy conversion. Renew. Energy 2004, 29, 529-547. [CrossRef]

52. Taha, Z.; Sugiyono; Ya, T.M.Y.S.T.; Sawada, T. Numerical investigation on the performance of Wells turbine with non-uniform tip clearance for wave energy conversion. Appl. Ocean Res. 2011, 33, 321-331. [CrossRef]

53. Guénette, V.; Houde, S.; Ciocan, G.D.; Dumas, G.; Huang, J.; Deschênes, C. Numerical prediction of a bulb turbine performance hill chart through RANS simulations. In Proceedings of the 26th IAHR Symposium on Hydraulic Machinery and Systems (IHAR 2012), Beijing, China, 19-23 August 2012.

54. Kim, S.; Choi, C.; Kim, J.; Park, J.; Baek, J. Effects of tip clearance on performance and characteristics of backflow in a turbopump inducer. Proc. Inst. Mech. Eng. Part A J. Power Energy 2013, 227, 847-857. [CrossRef]

55. Kim, S.; Choi, C.; Kim, J.; Park, J.; Baek, J. Tip clearance effects on cavitation evolution and head breakdown in turbopump inducer. J. Propuls. Power 2013, 29, 1357-1366. [CrossRef]

56. Torre, L.; Pasini, A.; Cervone, A.; Pace, G.; Miloro, P.; D’Agostino, L. Effect of tip clearance on the performance of a three-bladed axial inducer. J. Propuls. Power 2015, 27, 890-898. [CrossRef]

57. Kim, M.C.; Chun, H.H. Experimental investigation into the performance of the axial-flow-type waterjet according to the variation of impeller tip clearance. Ocean Eng. 2007, 34, 275-283. [CrossRef] 
58. Ding, Y.; Song, B.; Peng, W. Numerical investigation of tip clearance effects on the performance of ducted propeller. Int. J. Nav. Archit. Ocean Eng. 2015, 7, 795-804.

59. Oweis, G.F.; Fry, D.; Chesnakas, C.J.; Jessup, S.D.; Ceccio, S.L. Development of a tip-leakage flow-Part 1: The flow over a range of Reynolds numbers. J. Fluids Eng. 2006, 128, 751-764. [CrossRef]

60. Oweis, G.F.; Fry, D.; Chesnakas, C.J.; Jessup, S.D.; Ceccio, S.L. Development of a tip-leakage flow part 2: Comparison between the ducted and un-ducted rotor. J. Fluids Eng. 2006, 128, 765-773. [CrossRef]

61. Lu, L.; Pan, G.; Wei, J.; Pan, Y. Numerical simulation of tip clearance impact on a pumpjet propulsor. Int. J. Nav. Archit. Ocean Eng. 2016, 8, 219-227. [CrossRef]

62. Lu, L.; Gao, Y.; Li, Q.; Du, L. Numerical investigations of tip clearance flow characteristics of a pumpjet propulsor. Int. J. Nav. Archit. Ocean Eng. 2017, 10, 307-317. [CrossRef]

63. Koirala, R.; Zhu, B.; Neopane, H.P. Effect of guide vane clearance gap on francis turbine performance. Energies 2016, 9, 275. [CrossRef]

64. Egusquiza, E.; Valero, C.; Huang, X.; Jou, E.; Guardo, A.; Rodriguez, C. Failure investigation of a large pump-turbine runner. Eng. Fail. Anal. 2012, 23, 27-34. [CrossRef]

65. Ran, H.; Luo, X.; Lei, Z.; Zhang, Y.; Wang, X.; Xu, H. Experimental study of the pressure fluctuations in a pump turbine at large partial flow conditions. Chin. J. Mech. Eng. 2012, 25, 1205-1209. [CrossRef]

66. Tan, L.; Zhu, B.S.; Cao, S.L.; Wang, Y.C.; Wang, B.B. Numerical simulation of unsteady cavitation flow in a centrifugal pump at off-design conditions. ARCH. Proc. Inst. Mech. Eng. Part C J. Mech. Eng. Sci. 1994, 228, 1994-2006.

67. Wang, Y.; Tan, L.; Wang, B.; Cao, S.; Zhu, B. Numerical investigation on frequency jump of flow over a cavity using large eddy simulation. J. Fluids Eng. 2015, 137, 081203. [CrossRef]

68. Tan, L.; Zhu, B.; Wang, Y.; Cao, S.; Gui, S. Numerical study on characteristics of unsteady flow in a centrifugal pump volute at partial load condition. Eng. Comput. 2015, 32, 1549-1566. [CrossRef]

69. Rodriguez, C.G.; Mateosprieto, B.; Egusquiza, E. Monitoring of Rotor-Stator Interaction in Pump-Turbine Using Vibrations Measured with On-Board Sensors Rotating with Shaft. Shock Vib. 2014, 2014, 118-124. [CrossRef]

70. Liu, Y.; Tan, L.; Liu, M.; Hao, Y.; Xu, Y. Influence of prewhirl angle and axial distance on energy performance and pressure fluctuation for a centrifugal pump with inlet guide vanes. Energies 2017, 10, 695. [CrossRef]

71. Tan, L.; Yu, Z.; Xu, Y.; Liu, Y.; Cao, S. Role of blade rotational angle on energy performance and pressure fluctuation of a mixed-flow pump. Proc. Inst. Mech. Eng. Part A J. Power Energy 2017, 231, 227-238.

72. Zhang, W.; Yu, Z.; Zhu, B. Influence of tip clearance on pressure fluctuation in low specific speed mixed-flow pump passage. Energies 2017, 10, 148. [CrossRef]

73. Xu, Y.; Tan, L.; Liu, Y.; Cao, S. Pressure fluctuation and flow pattern of a mixed-flow pump with different blade tip clearances under cavitation condition. Adv. Mech. Eng. 2017, 9. [CrossRef]

74. Guo, S.; Okamoto, H. An experimental study on the fluid forces induced by rotor-stator interaction in a centrifugal pump. Int. J. Rotat. Mach. 2003, 9, 135-144. [CrossRef]

75. González, J.; Parrondo, J.; Santolaria, C.; Blanco, E. Steady and unsteady radial forces for a centrifugal pump with impeller to tongue gap variation. J. Fluids Eng. 2006, 128, 454-462. [CrossRef]

76. Hao, Y.; Tan, L.; Liu, Y.; Xu, Y.; Zhang, J.; Zhu, B. Energy performance and radial force of a mixed-flow pump with symmetrical and unsymmetrical tip clearances. Energies 2017, 10, 57. [CrossRef]

77. Gopalan, S.; Katz, J.; Liu, H.L. Effect of gap size on tip leakage cavitation inception, associated noise and flow structure. J. Fluids Eng. 2002, 124, 994-1004. [CrossRef]

78. Guo, Q.; Zhou, L.; Wang, Z. Numerical evaluation of the clearance geometries effect on the flow field and performance of a hydrofoil. Renew. Energy 2016, 99, 390-397. [CrossRef]

79. Wu, S.; Shi, W.; Zhang, D.; Yao, J.; Cheng, C. Influence of blade tip rounding on tip leakage vortex cavitation of axial flow pump. In Proceedings of the 6th International Conference on Pumps and Fans with Compressors and Wind Turbines (ICPF 2013), Beijing, China, 19-22 September 2013.

80. Mei, L.; Zhou, J. Effects of blade tip foil thickening on tip vortexes in ducted propeller. In Proceedings of the 3rd International Conference on Material, Mechanical and Manufacturing Engineering (IC3ME 2015), Guangzhou, China, 27-28 June 2015.

81. Tan, L.; Xie, Z.; Liu, Y.; Hao, Y.; Xu, Y. Influence of T-shape tip clearance on performance of a mixed-flow pump. Proc. Inst. Mech. Eng. Part A J. Power Energy 2018, 232, 386-396. 
82. Liu, Y.; Tan, L. Method of C groove on vortex suppression and energy performance improvement for a NACA0009 hydrofoil with tip clearance in tidal energy. Energy 2018, 155, 448-461. [CrossRef]

83. Roussopoulos, K.; Monkewitz, P.A. Measurements of tip vortex characteristics and the effect of an anti-cavitation lip on a model kaplan turbine blade. Flow Turbul. Combust. 2000, 64, 119-144. [CrossRef]

84. Gesaimart, W.S. Tip clearance cavitation in shrouded underwater propulsors. J. Aircr. 2015, 3, $185-192$. [CrossRef]

85. Yang, X.; Qin, Y.; Qu, Z. Leakage loss study of a synchronal rotary multiphase pump with a full range of inlet gas volume fractions. J. Fluids Eng. 2016, 138, 071301-071301-11. [CrossRef]

86. Ganesh, H.; Chang, N.; Ceccio, S. Tip vortex cavitation suppression by mass injection. J. Fluids Eng. 2011, 133, 337-340.

87. Rivetti, A.; Angulo, M.; Lucino, C.; Liscia, S. Pressurized air injection in an axial hydro-turbine model for the mitigation of tip leakage cavitation. In Proceedings of the 9th International Symposium on Cavitation (CAV 2015), Lausanne, Switzerland, 6-10 December 2015.

(c) 2018 by the authors. Licensee MDPI, Basel, Switzerland. This article is an open access article distributed under the terms and conditions of the Creative Commons Attribution (CC BY) license (http://creativecommons.org/licenses/by/4.0/). 